\title{
Proteostasis Dysfunction in Aged Mammalian Cells. The Stressful Role of Inflammation
}

\author{
Diego Ruano ${ }^{1,2 *}$ \\ ${ }^{1}$ Instituto de Biomedicina de Sevilla (IBiS), Hospital Universitario Virgen del Rocio/Consejo Superior de Investigaciones Científicas/ \\ Universidad de Sevilla, Sevilla, Spain, ${ }^{2}$ Departamento de Bioquímica y Biología Molecular, Facultad de Farmacia, Universidad de \\ Sevilla, Sevilla, Spain
}

\section{OPEN ACCESS}

Edited by:

Niki Chondrogianni,

National Hellenic Research

Foundation, Greece

Reviewed by:

Anna Gioran,

National Hellenic Research

Foundation, Greece

Frédéric Ebstein

Universitätsmedizin Greifswald,

Germany

Annika Höhn,

German Institute of Human Nutrition

Potsdam-Rehbruecke (DIfE), Germany

*Correspondence:

Diego Ruano

ruano@us.es

Specialty section:

This article was submitted to

Cellular Biochemistry,

a section of the journal

Frontiers in Molecular Biosciences

Received: 26 January 2021

Accepted: 28 May 2021

Published: 17 June 2021

Citation:

Ruano D (2021) Proteostasis Dysfunction in Aged Mammalian Cells. The Stressful Role of Inflammation.

Front. Mol. Biosci. 8:658742. doi: 10.3389/fmolb.2021.658742
Aging is a biological and multifactorial process characterized by a progressive and irreversible deterioration of the physiological functions leading to a progressive increase in morbidity. In the next decades, the world population is expected to reach ten billion, and globally, elderly people over 80 are projected to triple in 2050. Consequently, it is also expected an increase in the incidence of age-related pathologies such as cancer, diabetes, or neurodegenerative disorders. Disturbance of cellular protein homeostasis (proteostasis) is a hallmark of normal aging that increases cell vulnerability and might be involved in the etiology of several age-related diseases. This review will focus on the molecular alterations occurring during normal aging in the most relevant protein quality control systems such as molecular chaperones, the UPS, and the ALS. Also, alterations in their functional cooperation will be analyzed. Finally, the role of inflammation, as a synergistic negative factor of the protein quality control systems during normal aging, will also be addressed. A better comprehension of the age-dependent modifications affecting the cellular proteostasis, as well as the knowledge of the mechanisms underlying these alterations,

Abbreviations: ALFY, Autophagy-linked FYVE protein; ALS, Autophagy-lysosomal system; AMPK, AMP activated protein kinase; ATF4, Activating transcription factor 4; ATF6a, Activating transcription factor 6a; ATG, Autophagy-related genes; BAG, Bcl-2-associated ethnogeny; CHIP, Carboxyl terminus of HSc70-interacting protein; CHOP, C/EBP-homologous protein CMA, Chaperone-mediated autophagy; CREBH, Cyclic AMP Response Element-binding Protein H; DRiPs, Defective ribosomal products; eIF2 $\alpha$, Eukaryotic translation initiation factor 2 alpha; ER, Endoplasmic reticulum; ERAD, Endoplasmic reticulum-associated degradation; ERK, Extracellular signal-regulated kinase; ERdj4, Endoplasmic reticulum-localized DnaJ 4, ERp, Endoplasmic reticulum protein; FOXO3A, Forkhead Box O3A; GRP, Glucose-regulated protein; GSK, Glycogen synthase kinase; HDAC6, Histone deacetylase 6; HECT, Homologous to the E6-AP C-terminus; HIP, Hsp70 interacting protein; HOP, Hsp70-Hsp90 organizing protein; HRD, Hidroxi-metil-glutaril-CoA reductase degradation protein; HSP, Heat shock proteins; HSc, Heat shock cognate; IGF1, Insulin-like growth factor-1; IL-1 $\beta$, Interleukin-1 beta; IRE1 $\alpha$, Inositol-requiring enzyme 1 $\alpha$; JNK, c-Jun N-terminal kinase; Keap1,Kelch-like ECH-associated protein 1; LAMP, Lysosome-associated membrane protein; LC3-II, Microtubule-associated protein 1 light chain 3 alpha-II; LIR, LC3-interacting region; LPS, Lipopolysaccharide; MAPK, Mitogen-activated protein kinase; MCF7, Michigan Cancer Foundation-7; MDA-MB, M.D. Anderson-Metastasis breast cancer; mTOR, Mechanistic target of rapamycin; NBR1, Neighbor of BRCA1 gene 1; NDP52, Nuclear dot protein 52; NFk-B, Nuclear factor kappa-light-chain-enhancer of activated B cells; Nrf2, Nuclear factor erythroid 2-related factor 2; OPTN, Optineurin; PA28, Proteasome activator 28; PAC2, Proteasome Assembly Chaperone 2; PDI, Protein disulfide isomerase; PERK, Protein kinase RNA-like ERK; POMP, Proteasome maturation protein; PPP3, Protein phosphatase 3; Rpn, Regulatory particle nonATPase; Rpt, Regulatory particle ATPase; RING, Really interesting new gene; SIRT-1, Silent information regulator two ortholog-1; SEL1L, Suppressor/enhancer of Lin-12-like; SQSTM1, Sequestosome 1; TNF- $\alpha$, Tumor necrosis factor-alpha; TRAF2, TNF receptor-associated factor 2; TREM-1, Triggering receptor expressed on myeloid cells-1; TFEB, Transcription factor EB; ULK1, Unc-51 like autophagy activating kinase 1; UPR, Unfolded protein response; UPS, Ubiquitin proteasome system; VCP, Valosin-containing protein; XBP-1, X-box binding protein 1. 
might be very helpful to identify relevant risk factors that could be responsible for or contribute to cell deterioration, a fundamental question still pending in biomedicine.

Keywords: aging, proteasome, autophagy, inflammation, proteostasis, cell stress and aging

\section{INTRODUCTION}

\section{Protein Quality Control Systems}

Proteostasis is the dynamic regulation of a balanced, functional proteome, in order to maintain its functionality. In eukaryotic cells, proteostasis is maintained by different quality control systems such as molecular chaperones, the UPS, and the ALS. The correct function and coordination of all of them guarantee that proteins can be properly synthesized, folded, assembled, subcompartmentalized, and finally degraded according to cellular requirements.

\section{Molecular Chaperones}

Molecular chaperones are ubiquitous and highly conserved proteins. They include an array of different molecular weight proteins, ranging from ten to more than $100 \mathrm{kDa}$, distributed in different cellular compartments (Kampinga et al., 2009; Ciechanover and Kwon 2017). In particular, the human chaperome involves 332 genes that can be grouped into nine functional families: HSP90, HSP70, HSP60, HSP40, small HSPs, tetratricopeptide repeat-domain-containing, prefoldin, and ER and mitochondria specific chaperones (see Brehme et al., 2014 for a detailed review). Molecular chaperones promote efficient de novo protein folding, prevent aggregation of mis/unfolded proteins (Hartl et al., 2011; Kim Y.,E. et al., 2013), disaggregate aggregated proteins (Weibezahn et al., 2005), and target misfolded proteins for refolding or protein degradation (Pickart and Cohen, 2004). They bind to substrate proteins through exposed hydrophobic regions and/or unstructured polypeptide backbones, two hallmarks of non-native conformations. For example, HSP70, one of the most abundant cellular chaperones, participates in de novo protein folding, post-translational refolding of aggregation-prone proteins, and the re-solubilization of protein aggregates (Mayer and Gierasch, 2019). In summary, chaperones have pivotal roles in proteostasis from protein synthesis to protein degradation.

\section{The Ubiquitin Proteasome System}

The UPS is responsible for the catalysis of the ATP-dependent degradation of most of the soluble and short-lived polyubiquitinated proteins by the $20 \mathrm{~S}$ proteasome. The $20 \mathrm{~S}$ proteasome is a hollow barrel-shaped structure built of four rings: two outer $\alpha$-rings, and two inner $\beta$-rings, each one containing seven subunits ( $\alpha$ l to $\alpha 7$ or $\beta 1$ to $\beta 7$ ). The $\alpha$-rings control the substrate access to the proteolytic chamber, whereas the $\beta$-rings harbor the constitutive catalytic subunits: $\beta_{1}$ (caspaselike activity), $\beta_{2}$ (trypsin-like activity), and $\beta_{5}$ (chymotrypsin-like activity). The $20 \mathrm{~S}$ proteasome mainly degrades either nonubiquitinated misfolded, oxidized or damaged proteins (Raynes et al., 2016). However, the 20S proteasome (the proteolytic module) can associate with one or two terminal regulatory particle/s called $19 \mathrm{~S}$, giving rise to the $26 \mathrm{~S}$ or $30 \mathrm{~S}$ proteasome, respectively, which is responsible for the degradation of soluble and short-lived poly-ubiquitinated proteins (Rechsteiner and Hill, 2005; Ding and Yin, 2008; Jung and Grune, 2012). The $19 \mathrm{~S}$ regulatory particle is terminally attached to the $20 \mathrm{~S}$ core and is built of two different structures: a ring-shaped base and a mobile lid structure. The ring-shaped base is made up of ten different subunits: the Rpt1Rpt6 ring, and Rpn1, Rpn2, Rpn10, and Rpn13), whereas the lid structure includes nine additional subunits (Rpn3, Rpn5, Rpn6, Rpn7, Rpn8, Rpn9, Rpn11, Rpn12, and Rpn15), each one with different functions (Tanaka 2009). For example, the Rpt1-Rpt6 ring has ATPase activity and regulates substrate unfolding and substrate transfer through the channel. (Collins and Goldberg, 2017). The Rpn10 and Rpn13 possess ubiquitin-binding domains and functions as receptor for ubiquitinated substrates, whereas the Rpn11 subunit is a de-ubiquitinating enzyme that removes poly-ubiquitin chains from target proteins, allowing the release and re-use of ubiquitin molecules (Finley, 2009). Thus, the 19S particle can bind poly-ubiquitinated proteins, catalyze protein deubiquitination, unfold the target protein, and promote protein degradation into the catalytic chamber.

Proteins degraded by the $26 \mathrm{~S}$ proteasome, need to be previously tagged with ubiquitin in a process called protein ubiquitination (Ciechanover and Kwon 2017). This process involves the binding of ubiquitin to the target protein. Ubiquitin is a small and conserved protein of 76-amino acid residue, with seven residues of lysine located at positions $6,11,27$, 29, 33, 48, and 63. (Komander, 2009), that is mainly bound to lysine residues on the target protein, although it can also be attached to other residues such as Ser/Thr (Shimizu et al., 2010) Cys (Cadwell and Coscoy, 2005), or even to the N-terminus of the target protein (Breitschopf et al., 1998). First, ubiquitin is activated by the E1 enzyme (ubiquitin-activating), which catalyzes the ATP-dependent formation of a thioester bond between the C-terminal Gly carboxyl group of ubiquitin, and the Cys residue of the active site of the E1 enzyme. Then, ubiquitin is transferred to the Cys residue of a member of the E2 family of enzymes (ubiquitin-conjugating), and finally, substrate specificity is provided by specific E3 enzymes (ubiquitin ligase) of the E3 RING or HECT families. In general, four residues of ubiquitin bound through Lys-48 constitute the stronger degradation signal (Korovila et al., 2017) (see Figure 1 for a global overview).

In addition to the degradation of soluble cytosolic proteins, the UPS is also involved in the degradation of unfolded or misfolded proteins synthesized into the ER. It is estimated that around onethird of the total cellular proteins, secreted and transmembrane proteins, are synthesized and folded inside the ER (Braakman and Hebert, 2013). These proteins are especially dependent on 
A

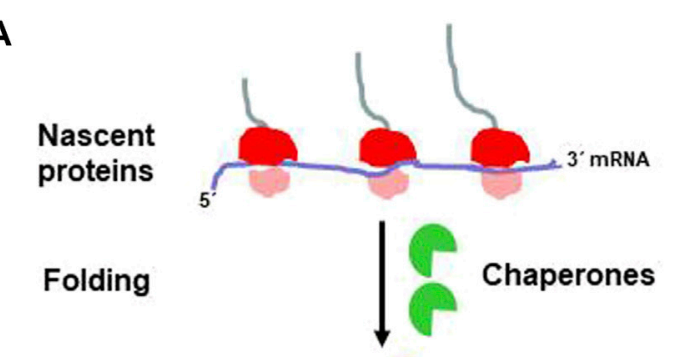

Native protein

Mislfolded Damaged Toxic Unnecessary proteins
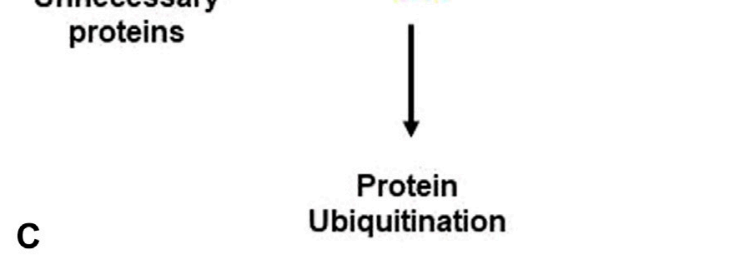
function
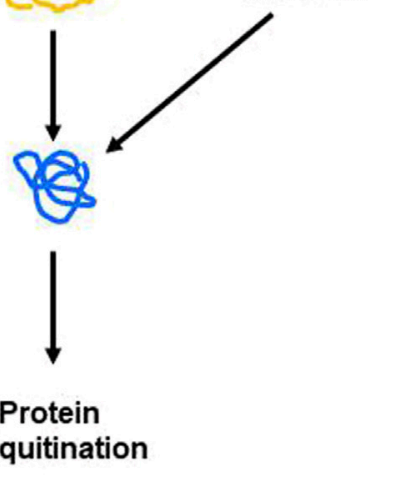

B

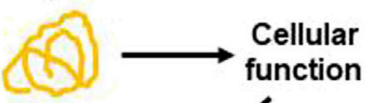

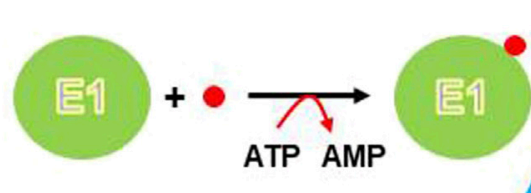

- Ubiquitin

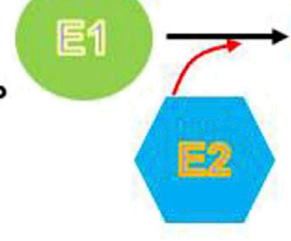

FIGURE 1 | Schematic representation of the cellular biology of proteins. mRNA translation produces nascent proteins that are assisted during folding by chaperones. Native proteins perform their cellular functions and are subject to cellular turnover (A). Also, unfolded, misfolded, oxidative damage, modified, or unnecessary proteins are targeted for degradation by the 26S or 30S proteasome [19S-20S or 19S-20S-19S, respectively: (B)]. Previous to proteasome degradation proteins need to be ubiquitinated by three enzymatic reactions catalyzed by the E1 (ubiquitin-activating), E2 ubiquitin-conjugating) and E3 (ubiquitin-ligase), respectively (C). UR. Ubiquitin receptor; DUBs. Deubiquitinating enzymes. $\beta 1, \beta 2$, and $\beta 5$. Catalytic subunits.

ER-specific chaperones that facilitate proper folding, modifications, and release from the ER (Ulrich et al., 2011; Gidalevitz et al., 2013). For example, GRP (glucose-regulated protein) 78 interacts with the unfolded nascent proteins, contributing to the translocation into the ER (Kleizen and Braakman, 2004). The oxidoreductase enzymes such as PDI, ERp57 or ERp44, catalyze the formation of disulfide bonds between cysteine residues during the folding of many proteins, providing structural stability and promoting the assembly of multi-protein complexes (Bulleid, 2012; Oka and Bulleid, 2013). If the folding capacity of the ER is reduced, proteins tend to accumulate producing a situation called ER stress. Under this challenge, cells up-regulate the expression of chaperones as part of a more complex compartment-specific stress response called the UPR. The UPR is initiated by three ER-resident membrane proteins: IRE1a, PERK, and ATF6a. Briefly, UPR activation results in i) the transcriptional up-regulation of genes coding for chaperones; ii) the attenuation of protein translation; and iii) the increase in the proteasomal and/or autophagy degradation of unfolded/misfolded proteins, through the ERAD (Fujita et al., 2007; Frakes and Dillin, 2017). Due to spatial separation between substrates and degradation systems, ERAD requires retrograde transport through the translocon of unfolded/misfolded proteins from the ER back to the cytosol (Meusser et al., 2005). In this case, substrates are targeted by specific ubiquitin ligases (E3 enzymes) such as the complex HRD1/HRD3 (Hampton et al., 1996; Kaneko and Nomura, 2003). In the end, this coordinate response has two major outcomes: proteostasis restoration or apoptotic cellular death (Gavilán et al., 2009b). 


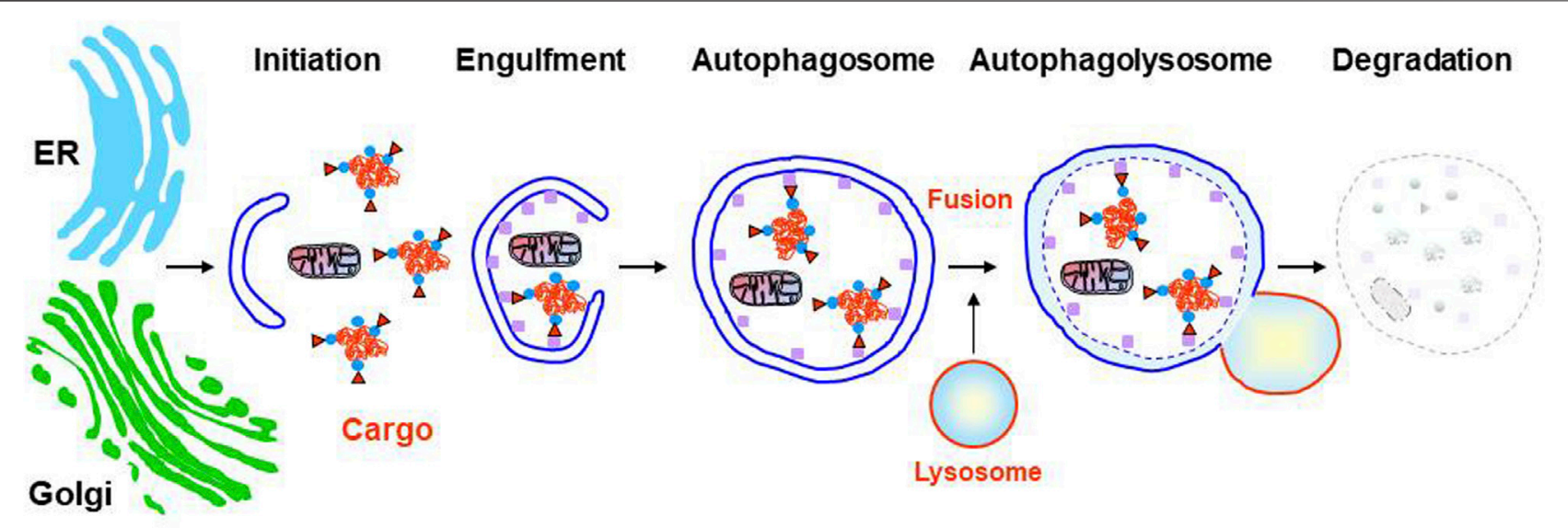

LC3II p62/SQTMS

Ubiquitin

Aggregated proteins

FIGURE 2 | Stages of the autophagy lysosomal pathway. From initiation to resolution the most relevant markers are shown. Two potential sources of autophagosome membranes, but not the only ones, are indicated: ER (endoplasmic reticulum) or Golgi.

\section{The Autophagy-Lysosomal System}

The ALS includes three different types of autophagic degradation, all of them ultimately depending on functional lysosomes, but each one acting through different molecular mechanisms (see Galluzzi et al., 2017 for an exhaustive review). Briefly, microautophagy is characterized by the direct capture of cytoplasmic fractions that are taken up by lysosomal membrane invaginations for their degradation (Mizushima et al., 2008). The mechanisms regulating microautophagy in mammalian cells are still poorly known (Mijaljica et al., 2011). CMA is involved in the selective degradation of specific soluble proteins by the lysosomes (Kaushik and Cuervo 2008). It involves neither vesicle formation nor membrane invaginations and participates in the degradation of cytosolic proteins containing the KFERQ sequence motif. The CMA-targeting motif is recognized in the cytosol by a chaperone complex including HSc70, HIP, HOP, BAG1, and HSP40, which assists protein translocation into the lysosomal lumen for their degradation in a LAMP2dependent manner (Cuervo et al., 2014). Finally, macroautophagy (referred to here as autophagy) represents the most relevant form of autophagy (He and Klionsky 2009; Mizushima et al., 2008). Autophagy plays a protective role in various types of stressful contexts such as starvation, protein aggregation, and renewal of damaged or obsolete organelles. It involves the autophagosome formation, a double-membrane vesicle originated by elongation of a de novo formed membrane; the sequestration of cargo inside the autophagosome, such as cellular organelles, long-lived proteins and/or aggregated proteins; the seals of the autophagosome; and the transport by the microtubule system, to finally fuse with late lysosomes or endosomes, for cargo degradation, forming autolysosomes. (Ding and Yin, 2008) (Figure 2). The sources of autophagosome membrane in mammal cells are still under debate, and different cellular organelles such as ER, Golgi, mitochondria, or cell membrane, have been found to contribute as membrane donor for autophagosome formation depending on autophagy induction condition (see Wei et al., 2018 for more detailed information). In the last years, different selective forms of autophagic degradation have emerged such as mitophagy, pexophagy, nucleophagy, reticulophagy, ribophagy, aggrephagy, lipophagy, proteaphagy or lysophagy (Galluzzi et al., 2017). Regulation of autophagy is complex, and it has been extensively investigated. The initiation, nucleation, and elongation phases are specifically regulated by different proteins, cellular pathways, and ATGs (see Carlsson and Simonsen, 2015 for a detailed review).

\section{FUNCTIONAL COOPERATION BETWEEN THE PROTEIN QUALITY CONTROL SYSTEMS}

Despite molecular mechanisms underlying the interplay between the UPS and autophagy are incompletely understood, there is solid evidence showing functional cooperation between the two major proteolytic systems under stress situations that are mediated by different cellular pathways (Korolchuk et al., 2010). This functional crosstalk allows the integration of many signals to provide a tailored cellular response to each specific cellular challenge (Figure 3). In addition to the functional cooperation of proteolytic systems, evidence also indicates a functional regulation between essential players of cellular proteostasis that cooperate with the two proteolytic systems such as chaperones, UPR, and ERAD. 


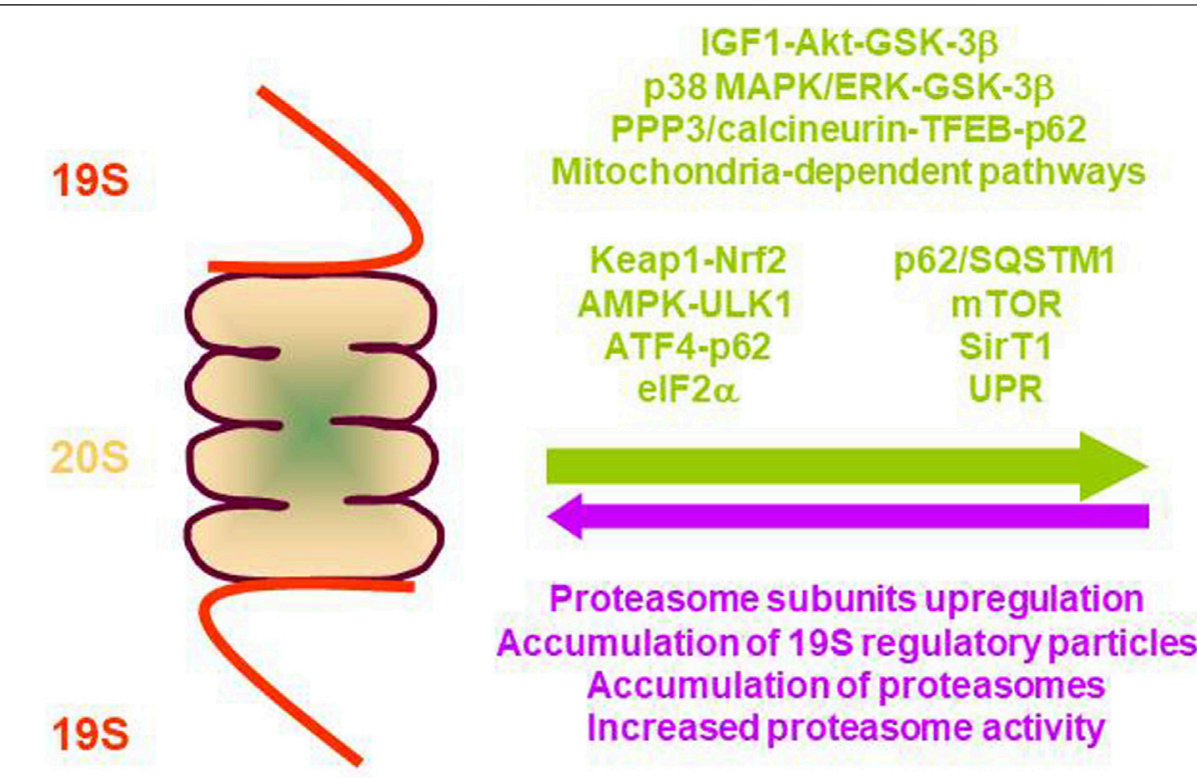

PROTEASOME 26/30S
p62/SQTMS
P38 MAPK/ERK-GSK-3 $\beta$

PPP3/calcineurin-TFEB-p62

Mitochondria-dependent pathways

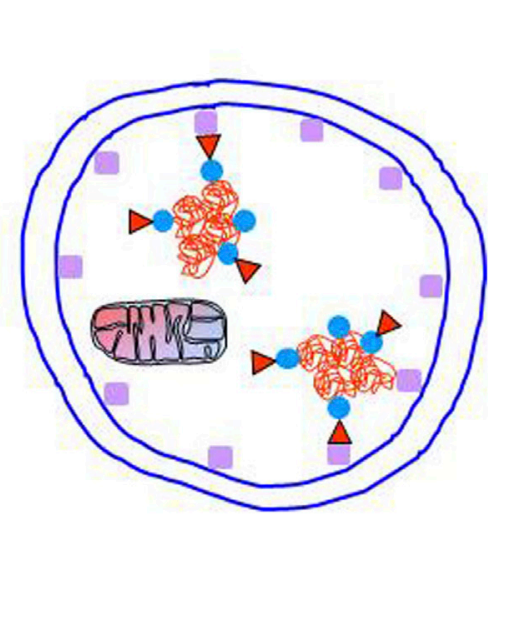

\section{Autophagosome}

functional cooperation from proteasome to autophagy (green) and from autophagy to proteasome (purple).

\section{Autophagy Compensation for Proteasome Dysfunction}

A general overview of available data indicates that proteasome impairment gives rise to autophagy activation. This functional cooperation has been demonstrated both in vitro and in vivo by different experimental approaches, such as pharmacological or genetic inhibition of the proteasome. However, the cellular pathways involved in this functional crosstalk are very complex and not well understood. A general overview of the pharmacological and genetic interventions is detailed.

\section{Pharmacological Approaches}

Different compounds are available to block proteasome activity such as MG132, lactacystin, bortezomib, or epoxomicin. Pharmacological inhibition of proteasome with the irreversible proteasome inhibitor lactacystin in rat hippocampus, upregulated the expression of several ATG, the SQSTM1/p62 (referred to here as p62), and increased autophagic activity through activation of the IGF1-AKT-GSK-3 $\beta$ pathway (Gavilán et al., 2015). A similar effect was described in mouse brain, heart, kidney, and liver using the reversible proteasome inhibitor MG132 or bortezomib, a selective and potent inhibitor of the proteasome with broad anti-tumor activities in many malignancies (Zheng et al., 2011). Other works have shown that MG132 induced autophagy activation in several cell lines through different cell signaling pathways. For example, in MDAMB-231 human breast epithelial cells, by activating the p38 MAPK/ERK-GSK-3 $\beta$ pathway (Choi et al., 2012), in human breast cancer epithelial cells MCF7, through activation of the AKT-GSK-3 $\beta$ pathway (Gavilán et al., 2013) or in macrophages, epithelial and endothelial cells, by modulating the mitochondrial/ AMPK signaling axis (Jiang et al., 2015). Treatment with bortezomib, induced protective autophagy in pancreatic and colorectal cancer cells through AMPK-ULK1 signaling (Min et al., 2014), and in melanoma cells, by both ER and mitochondrial-dependent pathways (Selimovic et al., 2013). Similarly, treatment with MG132 or bortezomib in human colon cancer cells produced ER-stress and UPR dependent autophagy activation. Autophagy was abolished by IRE1a knockdown, or by treatment with the JNK inhibitor SP600125 (Ding et al., 2007), but was independent of XBP-1 signaling (Ding et al., 2007; Rui et al., 2015). Finally, proteasome inhibition with bortezomib in human prostate cancer cells, and immortalized mouse embryonic fibroblasts promoted autophagy activation and upregulated expression of ATG5 and ATG7, which depended on 
phosphorylation of eIF2 $\alpha$, a downstream element of the PERK arm of the UPR (Zhu et al., 2010).

\section{Genetic Approaches}

Different targets and strategies have been used to induce proteasomal dysfunction. Elimination of the proteasome activator REG $\gamma$ in mice produced protective autophagy activation against high-fat diet-induced liver steatosis, mediated by SIRT-1-dependent deacetylation of ATG5 and ATG7 (Dong et al., 2013). Knockdown of the proteasome subunit $\beta 2$ in mice cardiomyocytes, induced autophagy activation, and increased mTOR expression and ER stress (Kyrychenko et al., 2014). Conditional knock-out mice of the ATPase subunit of the 19S particle Rpt2, increased protective autophagy by activation of the Keap1-Nrf2 pathway in a p62 phosphorylation-dependent manner, in both mouse liver and brain cortical neurons (Kageyama et al., 2014; Ugun-Klusek et al., 2017). However, genetic ablation of Rpt2 in mouse cardiomyocytes also activated autophagy but through the PPP3/calcineurin-TFEB-p62 pathway (Pan et al., 2020). Knockdown of proteasomal catalytic subunits in human prostate cancer cells and immortalized mouse embryonic fibroblasts promoted autophagy activation and upregulated expression of ATG5 and ATG7 (Zhu et al., 2010). Finally, knockdown of the proteasomal ubiquitin receptors Rpn10 and Rpn13 resulted in autophagy activation and ATF4-p62-dependent clearance of ubiquitinated proteins (Demishtein et al., 2017).

Thus, pharmacological, and genetic data provide solid evidence indicating a robust compensation of autophagy under proteasome dysfunction. Although the mechanisms connecting both proteolytic systems are complex, it is relevant to highlight the role of specific proteins acting as mechanical linkers between both proteolytic systems. They include p62, HDAC6, NBR1, NDP52, OPTN, vcp/p97, Alfy, and BAG proteins (Rogov et al., 2014; Cecarini et al., 2016). For example, the BAG1 and BAG3 proteins participate in protein delivery to the proteasome or the autophagy, respectively (Gamerdinger et al., 2009; Gavilán et al., 2013; Stürner and Behl, 2017). Under normal conditions, most of the polyubiquitinated proteins are degraded by the proteasome in an HSc/HSP70-BAG1 dependent manner (Luders et al., 2000; Demand et al., 2001). But under proteotoxic stress, proteins can accumulate and aggregate leading to increased autophagic activity (Stürner and Behl, 2017). In this case, BAG3, acting in concert with the multi-adapter protein $\mathrm{p} 62$, facilitates autophagic degradation (Behl 2016). The p62 protein can bind simultaneously to ubiquitinated proteins, through its UBA domain, to LC3-II, by its LIR domain (Katsuragi et al., 2015) and, to the co-chaperones HSc/HSP70. Thus, p62 would play a pivotal role in the molecular crosstalk between both proteolytic systems, integrating the signals coming from different cellular pathways (Myeku and Figueiredo-Pereira, 2011; Liu et al., 2016; Danieli and Martens, 2018; Aragonès et al., 2020).

\section{Proteasome Compensation for Autophagy Dysfunction}

There is also evidence indicating that autophagy and CMA dysfunction leads to proteasome compensation. For example, in cultured human colon cancer cells, autophagy disruption by RNA interference of ATG genes up-regulated transcriptional expression of proteasomal subunits, including the catalytic $\beta 5$ subunit, as well as proteasomal activities (Wang et al., 2013). Similarly, in the liver from mice with defective CMA, generated by genetic ablation of LAMP$2 \mathrm{~A}$, basal proteostasis was compensated by proteasomal activity due to increased content of the 19S regulatory particle (Schneider et al., 2015). However, there are also data indicating the lack of proteasome compensation for autophagy dysfunction. For example, in fibroblasts from autophagy-deficient mice $\left(A \operatorname{tg} 5^{-1-}\right)$, it was not observed any modifications in the three proteasomal activities (Kaushik et al., 2008), as well as in neurons from mice lacking Atg7 (Komatsu et al., 2006), or in the liver from conditional knockout mice of Atg7, where neither proteasomal proteins nor proteasomal trypsin-like activity was modified (Komatsu et al., 2005). Moreover, autophagy inhibition increased proteasome substrates, due to the accumulation of the adaptor protein $\mathrm{p} 62$, which inhibited the delivery of ubiquitinated proteins to the proteasome (Korolchuk et al., 2009). Thus, proteasomal compensation from autophagy dysfunction might be organdependent.

\section{Compensation Between Chaperone-Mediated Autophagy and Autophagy}

Compensation between the different types of autophagy has also been observed. For example, the decline of CMA by reduction of LAMP-2A expression resulted in the activation of autophagy in cultured mouse fibroblasts (Massey et al., 2006), PC12 cells (Vogiatzi et al., 2008), and mice liver (Schneider et al., 2015). However, in other works CMA down-regulation, produced an accumulation of autophagic vacuoles in HeLa cells (GonzálezPolo et al., 2005), Similarly, dysfunction of CMA in LAMP-2 deficient mice was accompanied by an accumulation of autophagic vacuoles in many tissues, and the impairment of autophagic degradation of long-lived proteins in hepatocytes, suggesting autophagy dysfunction, instead of autophagy compensation (Tanaka et al., 2000). Moreover, a reduction in the proteolytic capacity of lysosomes from LAMP-2 deficient hepatocytes produced autophagy dysfunction, suggesting that LAMP-2 would be somehow necessary for a proper autophagy activity (Eskelinen et al., 2002). Finally, genetic, and pharmacological CMA blockage was not compensated by autophagy activity in neurons (Bourdenx et al., 2021), in mouse embryonic fibroblasts (Eskelinen et al., 2004), or 661W cells (Rodríguez-Muela et al., 2013).

On the contrary, in fibroblasts from autophagy-deficient mice $\left(A t g 5^{-/-}\right)$(Kaushik et al., 2008), as well as in retinal cells subjected to autophagy inhibition both in vivo and in vitro CMA was activated (Rodríguez-Muela et al., 2013). 


\section{Chaperones, Unfolded Protein Response, and Endoplasmic Reticulum-Associated Degradation Crosstalk}

Functional cooperation between other members of the protein quality control systems, in addition to proteolytic systems, has been also shown.

As stated before, chaperones are associated with protein folding but also participate in protein degradation by both the proteasome and autophagy. Different processes such as the previously mentioned CMA, or chaperone-assisted selective autophagy of aggregated proteins represent two examples of functional cooperation between chaperones and autophagy (Kaushik and Cuervo, 2012). Similarly, chaperones also deliver misfolded proteins for degradation by the UPS, a mechanism called chaperone-assisted proteasomal degradation (Esser et al., 2004; Kettern et al., 2010), where the role of the cochaperone and ubiquitin ligase CHIP in sorting proteins to refolding or to proteasomal degradation is of central importance (McDonough and Patterson, 2003). As mentioned above, chaperones such as BAG1 and BAG3 participate in protein delivery to the proteasome or the autophagy, respectively, placing chaperones in the middle of the crosstalk between the two cellular protein degradation systems (Park and Cuervo, 2013). However, cooperation of chaperones with proteasomal degradation occurs with cytoplasmic but not with nuclear proteasomal degradation (Samant et al., 2018).

Chaperones have also been shown to regulate the UPR activity in different manners. It is well established that the most abundant ER chaperone GRP78 inhibits UPR activation by binding to the three sensor proteins (Hetz and Papa., 2018). Moreover, the activity of IRE1 $\alpha$ is regulated through the binding to IRE1 $\alpha$ of several chaperones such as GRP78, PDIA6, and ERdj4, or HSP47, promoting repression or activation of this sensor protein, respectively (Eletto et al., 2014; Amin-Wetzel et al., 2017; Sepulveda et al., 2018). Also, PDIA5 selectively regulates ATF6a activation (Higa et al., 2014), and Erp57, by controlling the oxidative state of PDI, has been found to regulate PERK activity (Kranz et al., 2017). Thus, different cellular chaperones, working independently or together, can specifically regulate the three sensor proteins involved in UPR activation. Reciprocally, UPR activation in response to different stimuli, such as proteasome inhibition, gives rise to transcriptional upregulation of several ER-chaperones as well as ERAD markers to rescue or degrade misfolded proteins, respectively (Paz Gavilán et al., 2006; Walter and Ron, 2011; Sun et al., 2015).

Finally, ERAD might also regulate UPR. In this sense proteasomal degradation of IRE1 $\alpha$ is promoted by SEL1L-HRD1 ERAD components, indicating that IRE1 $\alpha$ is an ERAD substrate. Depletion of SEL1L or HRD1 in several cell types, increased the amount of IRE1a protein, without affecting transcriptional induction. Importantly, the interaction between IRE1 $\alpha$ and SEL1L in the basal condition is dependent on chaperones GRP78 and OS9 (Sun et al., 2015). On the contrary, IRE1a-XBP1 transcriptionally upregulates the expression of SEL1L and HRD1, indicating a bidirectional control between ERAD and UPR.

Altogether, these data indicate that protein quality control systems are functionally interconnected to re-establish proteostasis under proteotoxic stress. Moreover, the molecular versatility observed between the different protein quality control systems, as well as in the different cellular pathways mediating their functional cooperation, suggests that functional cooperation seems to be a cell type-specific process.

\section{AGE-RELATED ALTERATIONS IN THE PROTEIN QUALITY CONTROL SYSTEMS}

The progressive decline in the buffering capacity of the proteostasis network represents one of the molecular hallmarks of aging (López-Otin et al., 2013). However, the biological reasons why the proteostasis network deteriorates during aging are complex and not well understood. A progressive decrease in the activity and efficacy of the protein quality control systems, as well as in the mechanisms mediating the functional cooperation between them, could be the cause of these dysfunctions.

\section{Molecular Chaperones}

A general fact of molecular chaperones during aging is a progressive decline in their amount and/or activity, leading to a lower capacity to cope with cellular stress. A growing body of evidence has demonstrated that many cytosolic and ER chaperones, such as HSP70, HSc70, GRP78, PDI, calnexin, calreticulin, ERp55, ERp57, ERp72, Ero1-like protein alpha, and the family of the ATP-dependent cytosolic chaperones, down-regulate their expression in different cells and tissues, as well as in different organisms including humans (Table 1). However, for some other molecular chaperones, the basal transcriptional expression remains stable in aged cells (Erickson et al., 2006; Paz Gavilán et al., 2006; Brehme et al., 2014; Crum et al., 2015), or even increases (Lee at al., 1999; Brehme et al., 2014; Crum et al., 2015).

The decline in the expression of molecular chaperones during aging might reduce the protein folding capacity, increasing the number of unfolded/misfolded proteins in aged cells. For example, the accumulation of ubiquitinated proteins in the aged rat hippocampus following proteasome inhibition was higher in those animals that displayed the lower GRP78 up-regulation (Paz Gavilán et al., 2006). Similarly, in aged human postmortem samples, GRP78 co-localized more frequently with the enzyme tyrosine hydroxylase (healthy dopaminergic neurons), but not with $\alpha$-synuclein positive neurons (neurodegenerating neurons). By contrast, $\alpha$-synuclein positive neurons co-localized more frequently with caspase12 (Alladi et al., 2010). Also, inhibition of HSP70 in primary olfactory bulb cultures increased proteotoxicity induced by proteasome inhibition (Crum et al., 2015). However, in lymphoblasts from human centenarians up-regulation of HSP70 in response to heat shock was similar to that observed in young donors, and higher than in aged (non-centenarians) donors (Ambra et al., 2004). These data suggest a correlation of the level of expression of the molecular chaperones with the life span of differentiated cells.

On the other hand, the age-dependent decrease in the content of ER chaperones might affect specifically ERAD activity. In this sense, basal expression of the protein vcp/97, a component of ERAD that participates in the ATP-dependent extraction of misfolded proteins from ER for cytosolic proteasomal degradation, is increased in aged 
TABLE 1 | Representative molecular chaperones affected by aging in different tissues and organisms.

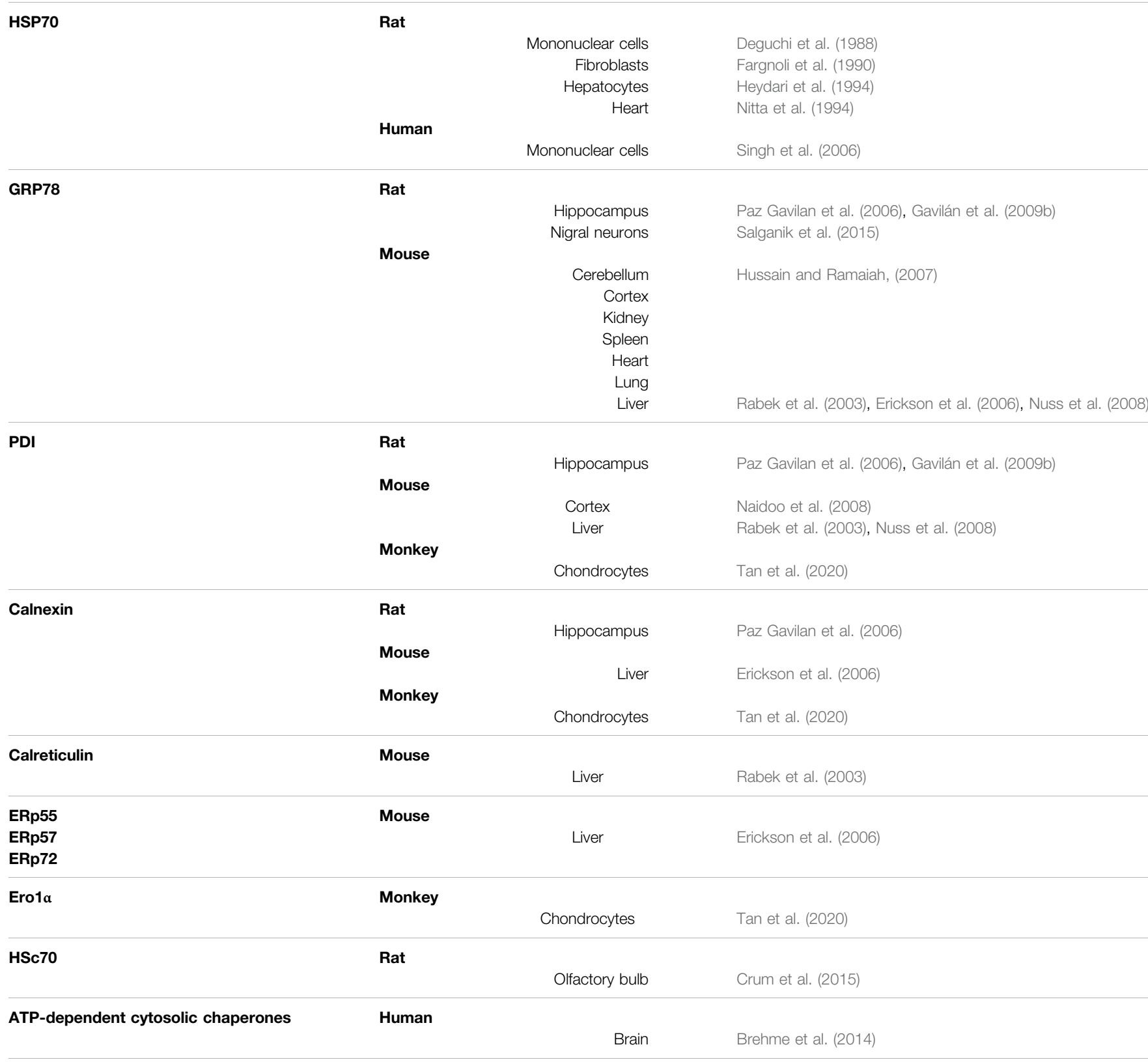

rats, suggesting augmentation of basal ER-stress (Pintado et al., 2017). In summary, considering the many cellular functions in which chaperones are involved, an adequate level of cellular chaperones is of crucial importance to get cellular healthy aging, in order to limit the decrease in tissue and cellular function.

The reasons leading to chaperome down-regulation are currently unknown. In this sense, age-related alterations in general transcriptional expression and translational efficiency have been described in mice (Lee et al., 2000), rats (Wood et al., 2013), and humans (Lu et al., 2004). Thus, future studies focused on age-related modifications in epigenomic mechanisms, such as transcription factor binding, histone marks, heterochromatin formation, and DNA methylation could shed light on the age-related modifications in the mechanisms regulating gene expression
(Booth and Brunet, 2016). Moreover, another possibility to explore would be if aggregated proteins in aged cells might catch molecular chaperones, a situation that might contribute to the collapse of proteostasis in aged cells (Yu et al., 2014).

\section{The Ubiquitin Proteasome System}

It is well documented that proteasome activity decreases during normal aging leading to oxidized and/or poly-ubiquitinated protein accumulation. This fact has been described by many groups in many tissues such as the spinal cord, cerebral cortex, kidney, lung (Keller et al., 2000a), hippocampus (Keller et al., 2000a; Gavilán et al., 2009b) liver (Conconi et al., 1996; Keller et al., 2000a) heart (Keller et al., 2000a; Bulteau et al., 2002) epidermis (Bulteau et al., 2000; Petropoulos et al., 2000), 
lymphocytes (Carrard et al., 2003), muscle (Bardag-Gorce et al., 1999; Radák et al., 2002; Husom et al., 2004; Ferrington et al., 2005), Achilles tendon (Radák et al., 2002), and fibroblasts (Merker et al., 2000), indicating that the gradual decline in the proteasomal activity is a hallmark of aging. However, it should be also noted that Giannini et al., 2013, demonstrated that purified $26 \mathrm{~S}$ proteasomes from aged rat brain and cerebellum, displayed lower activity than proteasomes from young animals, when using fluorogenic peptides, but exhibited no changes, or even slightly increased activity when a more physiological substrate was used (poly-Ub-model substrate).

The exact mechanisms accounting for the age-dependent decrease in the proteasome activity remain still elusive. For example, structural alterations of the proteasome, as well as reduced expression of proteasome subunits have been described (Lee et al., 1999; Bulteau et al., 2002; Chondrogianni et al., 2003; Gavilán et al., 2009a; Baraibar et al., 2012). On the other hand, the age-related increase in reactive oxygen species, mostly due to mitochondrial dysfunction and dysregulation of anti-oxidant repair mechanisms (Squier, 2001; Rottenberg and Hoke, 2017; Scialo et al., 2017), can also affect proteasome activity by oxidative damage. Every single alpha and beta subunits, as well as regulatory $19 \mathrm{~S}$ subunits, can be modified by oxidation (Korovila et al., 2017; Lefaki et al., 2017). Irreversible oxidative modifications such as the formation of 4-hydroxynonenalprotein adducts in specific proteasome subunits (Keller et al., 2000b; Petropoulos et al., 2000; Bulteau et al., 2001; Ferrington and Kapphahn, 2004; Wang et al., 2010), or the formation of protein carbonyls in the regulatory subunit S6 ATPase (Rpt5) of the 26S proteasome (Ishii et al., 2005), reduced proteasomal activity. Similarly, the reversible oxidative modification S-glutathionylation has been found in the Rpn2 regulatory subunit of the $26 \mathrm{~S}$ proteasome, leading to reduced proteasomal degradation of substrates (Zmijewski et al., 2009). But S-glutathionylation of the $20 \mathrm{~S}$ proteasome has also been proposed to act as a regulatory mechanism to remove oxidized proteins under oxidative stress, by inducing gate opening and enhancing proteasomal activity (Silva et al., 2012). In addition to these oxidative-induced modifications, oxidative stress can also promote other proteasomal modifications such as poly ADPribosylation, S-nitrosylation, phosphorylation, or ubiquitination, all of them decreasing proteasomal activity (Kors et al., 2019).

Another relevant role of oxidative stress on proteasome structure and function is the differential susceptibility to oxidative stress displayed by the $20 \mathrm{~S}$ and the $26 \mathrm{~S}$ proteasomes. For example, exposure of human hematopoietic K562 cells, yeast, or bovine lens epithelial cells, to several oxidants affected differently the proteolytic activity of the $20 \mathrm{~S}$ and the $26 \mathrm{~S}$ proteasomes. Whereas degradation of oxidized proteins by the $20 \mathrm{~S}$ proteasome was not affected, or even increased, degradation of ubiquitinated proteins by the $26 \mathrm{~S}$ proteasome was severely reduced or inhibited, suggesting that the $20 \mathrm{~S}$ proteasome is much more resistant to oxidative stress (Shang and Taylor, 1995; Reinheckel et al., 1998, Reinheckel et al., 2000; Wang et al., 2010).

However, other work in mouse embryonic fibroblasts indicated that under oxidative stress, the $26 \mathrm{~S}$ proteasome can degrade both oxidized and ubiquitinated proteins, and seemed to be equally resistant to oxidative stress than the $20 \mathrm{~S}$ proteasome (Haratake et al., 2016). Also, oxidative stress promotes the dissociation of the proteasome from the $26 \mathrm{~S}$ holoenzymes to free $20 \mathrm{~S}$ proteasome and the regulatory particle $19 \mathrm{~S}$, increasing the 20S/26S ratio (Wang et al., 2010; Grune et al., 2011; LivnatLevanon et al., 2014; Haratake et al., 2016; Wang et al., 2017). This process is conserved from yeast to human and is mediated, at least in part, by the protein Ecm29 (extracellular mutants 29) (Wang et al., 2010; Haratake et al., 2016; Wang et al., 2017). Considering that oxidatively damaged proteins are mostly degraded by the $20 \mathrm{~S}$ proteasome, the oxidative-induced increase in the 20S/26S ratio might represent a cellular adaptation to acute oxidative stress (Davies 2001; Grune et al., 2003; Pickering et al., 2010). However, under chronic oxidative stress, as occurring during normal aging, sustained dissociation of the $26 \mathrm{~S}$ proteasome might favor the accumulation of ubiquitinated proteins due to both reductions of the $26 \mathrm{~S}$ proteasome, and reduced activity of the oxidized $20 \mathrm{~S}$ proteasome (Ferrington et al., 2005). In this line, transcriptional up-regulation of several constitutive proteasome subunits has been found in aged rat muscle cells, in parallel with a reduction in the content of the proteasome activating proteins, PA28 and 19S (Ferrington et al., 2005). Also, the aged rat hippocampus increased the content of proteasome subunits, but decreased proteasomal activity, leading to the accumulation of ubiquitinated proteins (Paz Gavilán et al., 2006; Gavilán et al., 2009b). All these data could be compatible with a reduction in the amount of the $26 \mathrm{~S}$ proteasome in aged cells induced by chronic oxidative stress and/or chronic inflammation (see below). However, other possibilities cannot be ruled out.

In summary, the mechanisms accounting for the agedependent decrease in the proteasome activity seem to be heterogeneous and probably cell-type specific. The reduction in the number of cellular proteasomes, together with the oxidative damages of specific proteasome subunits could account for most of the age-dependent proteasomal dysfunctions occurring in aged cells. Moreover, proteasomal dysfunction and decreased chaperones activity have synergistic negative effects on the risk of protein accumulation. In turn, accumulated proteins might be prone to form proteins aggregates that cannot be degraded by the proteasome, but might physically block it, leading to a toxic vicious circle especially for post-mitotic cells such as neurons and muscles cells (Gregori et al., 1997; Bence et al., 2001; Grune et al., 2004; Oddo, 2008; Tseng et al., 2008; Höhn et al., 2011).

\section{The Autophagy-Lysosomal System}

Age-related dysfunctions in both autophagy and CMA have also been extensively documented in several tissues such as the liver, brain, and heart (Cuervo and Dice, 2000; Bergamini et al., 2004; Martinez-Vicente et al., 2005; Taneike et al., 2010). The factors accounting for the age-related autophagy dysfunctions in aged cells are also heterogeneous. For example, a reduced formation of autophagic vacuoles, in addition to the delay of fusion of autophagic vacuoles with lysosomes was observed in aged mouse hepatocytes (Terman, 1995). Similarly, in aged mouse retina autophagosome formation, as well as reduction of the LC3 flux, and p62 accumulation was observed (Rodríguez-Muela et al., 2013). 
Transcriptional down-regulation of many autophagy genes has been extensively documented in the aged human brain (Lipinski et al., 2010), muscle from aged Fischer 344 rats (Wohlgemuth et al., 2010), aged mouse retina (RodríguezMuela et al., 2013), and the hippocampus from aged Wistar rats (Gavilán et al., 2015). Additionally, reduced expression of proteins such as ATG5, ATG12, and Beclin-1 has also been observed in different old tissues (Rodríguez-Muela et al., 2013; Gavilán et al., 2015; Ott et al., 2016). Moreover, epigenetic factors have also been found to regulate autophagy (Füllgrabe et al., 2014; Lapierre et al., 2015; Baek and Kim 2017). For example, autophagy activation was associated with reduced acetylation of H4K16 (Füllgrabe et al., 2013), or increased H3R17 dimethylation (Shin et al., 2016), whereas H3K9 methylation by the histone methyltransferase G9a repressed the expression of LC3B, p62, and other autophagy-related genes (Artal-Martinez de Narvajas et al., 2013). Importantly, hypermethylation in the promoter regions of both the LC3 and ATG5 genes has been observed in macrophages from aged mice, leading to transcriptional downregulation (Khalil et al., 2016).

Finally, as mentioned before, the three arms of the UPR participates in autophagy activation (Kroemer et al., 2010), and basal activity of both UPR and autophagy decreased in aged rats (Paz Gavilán et al., 2006; Naidoo et al., 2008; Gavilán et al, 2009b; Gavilán et al., 2015). For example, the transcription factor sXBP1, a downstream marker of the IRE1a pathway, enhanced autophagy activity by transcriptional upregulation of Beclin-1 in endothelial cells and macrophages (Margariti et al., 2013; Tian et al., 2015), and levels of sXBP1 are decreased in aged rats (Naidoo et al., 2008; Gavilán et al., 2009b).

On the other hand, CMA activity is also decreased in different aged tissues such as the liver, heart, lung, or kidney (Dice, 1982; Cuervo and Dice, 2000; Kiffin et al., 2007; Schneider et al., 2015). In this case, modifications in the lipids of the lysosomal membrane, as well as in the membrane dynamic, and the amount and stability of the LAMP-2A protein at the lysosomal membrane, might be factors contributing to the age-dependent decline of CMA (Kaushik et al., 2006; Kiffin et al., 2007; Zhang and Cuervo, 2008; Rodriguez-Navarro et al., 2012). However, up-regulation of CMA in aged mouse retina has also been observed (Rodríguez-Muela et al., 2013).

Paradoxically, oxidative stress activates autophagy (ScherzShouval and Elazar, 2007; Lee et al., 2012) and CMA (Kiffin et al., 2004), probably as a homeostatic response to different acute stressors. However, during aging and under pathological oxidative stress, where oxidative stress became a chronic situation, autophagy activity is blocked as well as the nuclear translocation of TFEB, leading to mitochondrial fission and cellular death (Gavilán et al., 2015; Santin et al., 2016). One potential explanation for these opposed scenarios might be that sustained activation of autophagy could lead to autophagy exhaustion, eventually producing suppression of autophagy (Ho et al., 2016).

In summary, the age-related malfunction of protein quality control systems favors the accumulation of oxidized and/or polyubiquitinated proteins and increases cell vulnerability. This aspect is especially relevant in non-dividing cells such as neurons as it has been recently demonstrated (Bourdenx et al., 2021).

\section{Functional Cooperation}

The protein quality control systems form a functionally interdependent network that cooperates to maintain and restore cellular proteostasis under different stress situations. A relevant issue still not deeply analyzed is to evaluate the effect of aging on the functional cooperation between the protein quality control systems. The available data indicate that proteasomal inhibition was efficiently compensated by autophagy activation and resolution in young rat hippocampus, but not in aged animals, leading to proteostasis restoration in young, but protein aggregation and neurodegeneration in old animals (Gavilán et al., 2009b; Gavilán et al., 2015). Also, autophagy compensation in response to CMA dysfunction, observed in the liver from young mice, was lost in old mice (Schneider et al., 2015). Similarly, proteasome inhibition produced the canonical activation of the UPR as well as ERAD induction in young rats, but partial UPR activation (only the PERK pathway) and not ERAD induction in aged animals (Gavilán et al., 2009b; Pintado et al., 2017). Thus, aging seems to harm the functional cooperation between proteolytic pathways, suggesting that compensation might be effective in acute, but not in chronic stress situations such as aging. Indeed, proteasomal degradation in CMA-impaired cells was similar to control cells, but when blockage of CMA was sustained for more than 4 months, proteasomal degradation decreased, due to a reduction in proteasome activities, and to changes in the subunit composition of the 26S proteasome (Massey et al., 2006). Moreover, 26S proteasome dysfunction in Rpt2 knock-out mice was compensated by increased autophagy in 3 weeks old mice, but this compensation was lost in animals subjected to long-term $26 \mathrm{~S}$ proteasome dysfunction (6 weeks old mice), due to impairs of the Keap1-Nrf2 pathway (UgunKlusek et al., 2017). By contrast, other work found in the retina of old animals that CMA was upregulated in response to autophagy dysfunction (Rodríguez-Muela et al., 2013), suggesting that age-related deterioration of the functional compensation between the different protein quality control systems might be cell-type specific. Finally, an important question that remains to be answered is to know the molecular mechanisms underlying the age-dependent decline in functional cooperation. Current data indicate that defective signaling of the IGF1-AKT-GSK-3 $\beta$ - $\beta$-catenin pathway could account for the decrease in autophagy compensation in rat hippocampus in response to proteasome inhibition (Gavilán et al., 2015). And disrupted signaling of TFEB might be involved in defective compensation of autophagy in response to CMA dysfunction in liver mouse (Schneider et al., 2015).

In summary, these data support the idea that proteolytic systems form an intricate network that compensates each other to restore proteostasis. Age-dependent alterations of this functional crosstalk might compromise cellular viability. Since many different cellular pathways can modulate the functional cooperation between the protein quality control systems, future works using different cell types and stressors will be necessary, to 
better understand how aging is affecting functional cooperation. Because proteostasis alteration is also characteristic of some agedependent pathological disorders, the identification of prevalent factors contributing to the disruption of the functional cooperation between proteolytic systems will become a major challenge for biomedicine and geroscience for the coming years.

\section{INFLAMMATION}

Aging is also characterized by the presence of a low-grade chronic inflammation status called inflammaging (Franceschi et al., 2000). For example, the level of the pro-inflammatory cytokines IL-1 $\beta$, IL-6, TNF- $\alpha$, and C-reactive protein, are increased in aged organisms (Gavilán et al., 2007; Minciullo et al., 2012; Barrientos et al., 2015; Scheinert et al., 2015). Moreover, activated microglial cells (Gavilán et al., 2007), macrophages infiltration (Wolfe et al., 2018), as well as alterations in $\mathrm{T}$ cells and macrophages function (Vaughan and Peters, 1974; Sheng et al., 1998; Conde and Streit, 2006; Norden and Godbout, 2013), are characteristic of aging. Thus, aged cells are exposed to a chronic inflammatory environment that could affect their homeostatic response.

\section{Inflammation and the Protein Quality Control Systems}

A growing body of evidence indicates a complex and bidirectional association between protein quality control systems and inflammation. For example, Th1 or Th2 cytokines stimulated or inhibited autophagy, respectively (Wu et al., 2016). Also, TNF- $\alpha$ modulated proteasome and autophagy function in human skeletal muscle cells (Keller et al., 2011), and in synovial fibroblasts from rheumatoid arthritis (Connor et al., 2012). LPS-induced neuroinflammation produced ER-stress, altered proteasome and autophagy activity, and down-regulated ERAD markers (Liu X.,D. et al., 2012; Pintado et al., 2017). Moreover, up-regulation of ERAD markers induced by proteasome inhibition was abolished by LPS-induced inflammation (Pintado et al., 2017). Also, UPR activation has been found to increase the production of inflammatory cytokines. The three arms of the UPR: IRE1 $\alpha$ TRAF2, PERK-eIF2 $\alpha$, PERK-GSK-3, and ATF6-CREBH can activate the transcription factor NFK-B, which has a pivotal role in the onset of inflammation (Salminen et al., 2009; Vallabhapurapu and Karin, 2009 ). For example, NF- $\kappa \mathrm{B}$ activation and TNF- $\alpha$ synthesis, induced by ER stress, were impaired in IRE1 $\alpha$ knockdown mouse embryonic fibroblasts ( $\mathrm{Hu}$ et al., 2006). Also, activation of Toll-like receptors in macrophages induced specifically the IRE1 $\alpha$-XBP1 pathway and cytokine production (Martinon et al., 2010). However, activation of Toll-like receptors suppressed CHOP expression despite PERK activation (Woo et al., 2012). Moreover, recent work demonstrates that XBP-1 silencing in macrophages inhibited the production of IL- $1 \beta$, TNF- $\alpha$, and IL- 6 induced by TREM-1 activation, and reciprocally, TREM-1 activation-induced UPR in primary macrophages (Dong et al., 2021).

On the other hand, cytokines such as $\alpha$-interferon, $\gamma$-interferon, or TNFa promote the replacement of the catalytic subunits of the 20 S proteasome $\left(\beta_{1}, \beta_{2}\right.$, and $\left.\beta_{5}\right)$, by the inducible subunits $\beta_{1 \mathrm{i}}, \beta_{2 \mathrm{i}}$, and $\beta_{5 \mathrm{i}}$ (Gaczynska et al., 1993; Aki et al., 1994; Rivett et al., 2001; Gavilán et al., 2012; Jimenez-Guardeño et al., 2019). These subunits associate with the proteasome activator PA28 complex (also named $11 \mathrm{~S}$ ), forming a proteasome isoform called immunoproteasome (Chondrogianni and Gonos, 2007; Gavilán et al., 2012). The immunoproteasome is constitutively expressed in immune cells and compared with the $20 \mathrm{~S}$ proteasome has different proteolytic activities. Among other functions, the immunoproteasome participates in antigen presentation (Yang et al., 1995; Strehl et al., 2005; Chapiro et al., 2006), $\boldsymbol{\gamma}$-interferon-mediated microglial activation (Moritz et al., 2017), cytokine production by microglial cells (Wagner et al., 2017), or the maintenance, expansion, and regulation of T-cell population (Zaiss et al., 2008; Muchamuel et al., 2009; Moebius et al., 2010).

However, in addition to providing peptides for antigen presentation, and other immune functions, the immunoproteasome degrades nascent oxidant damaged proteins, also known as DRiPs (Seifert et al., 2010; Opitz et al., 2011), increases the cellular proportion of hydrophobic peptides (Gaczynska et al., 1996; Cascio et al., 2001; Chapiro et al., 2006 ; Paz Gavilán et al., 2006; Gavilán et al., 2009a), and regulates autophagy (Pintado et al., 2017; Karim et al., 2020). Thus, the immunoproteasome plays an important general role in the maintenance of cellular proteostasis under acute inflammation.

On the contrary, the protein quality control systems can also regulate the inflammatory response. For example, selective inhibition of the immunoproteasome subunit $\beta_{5 i}$ blocked the production of interferon- $\gamma$ and IL-2 by T cells, and interleukin-23 by activated monocytes (Muchamuel et al., 2009). Moreover, the recently described proteasome-associated autoinflammatory syndromes, such as Nakajo-Nishimura syndrome (Arima et al., 2011), lipodystrophy (Kitamura et al., 2011), or chronic atypical neutrophilic dermatosis (Liu Y. et al., 2012), are caused by inherited and/or de novo loss-of-function mutations affecting both constitutive and immunoproteasome subunits $(\alpha 7, \beta 2, \beta 7$, $\beta 1 \mathrm{i}, \beta 2 \mathrm{i}, \beta 5 \mathrm{i}$ ) (Sarrabay et al., 2020), or chaperone proteins (POMP, PAC2) (Brehm and Krüger, 2015; Poli et al., 2018; de Jesus et al., 2019). Finally, autophagy disruption is related to increased ER stress and the production of pro-inflammatory molecules (Ghosh et al., 2016).

In summary, these data indicate that inflammation and proteostasis are two processes mutually influenced. This functional relationship might be useful to fine-adjust the activity of both cellular processes to acute stress situations. However, chronic activation of inflammation might negatively affect the protein quality control systems avoiding proteostasis restoration.

\section{Inflammation and Proteostasis in Aged Cells}

Because aging is associated with a low grade of chronic inflammation, the modulation exerted by inflammation on cellular proteostasis might be particularly relevant in aged cells. For example, the immunoproteasome, which is not expressed in cells from young animals, is expressed in rat and human aged cells from several tissues (Ferrington et al., 2005; Mishto et al., 2006; Gavilán et al., 2007; Gavilán et al., 2009a; Wagner et al., 2017). 


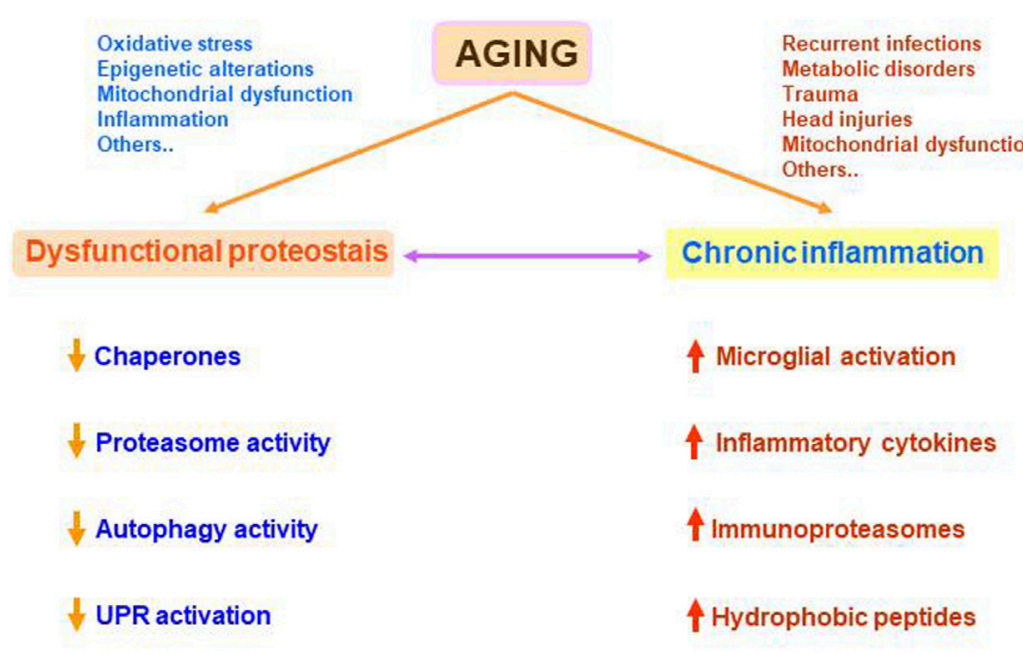

4 20S/26S proteasomes

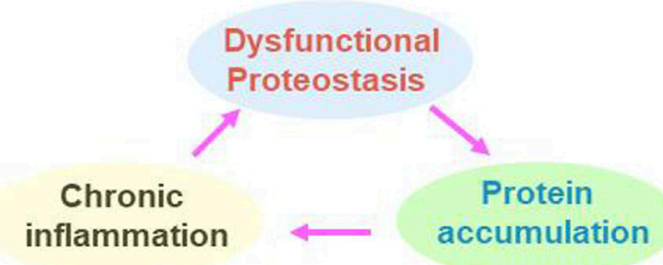

FIGURE 4 | Representation of the age-related alterations in cellular proteostasis and inflammation and their potential synergistic negative effects. Many different situations occurring all along the life can be involved in dysfunctional proteostasis and/or chronic inflammation. These two processes can be modulating each other leading to a vicious circle. Dysfunctional proteostasis leads to protein accumulation that can potentiate or sustains chronic inflammation. In turn, chronic inflammation potentiates dysfunctional proteostasis.

Moreover, proteasome turnover is regulated by neuroinflammation. Whereas in young rats, irreversibly damaged proteasomes were replaced with constitutive proteasomes, in aged rats they were replaced with immunoproteasomes (Gavilán et al., 2012). Also, the content of small hydrophobic peptides, mostly produced by the immunoproteasome (Gaczynska et al., 1996; Cascio et al., 2001; Chapiro et al., 2006 ; Gavilán et al., 2009a), increased in the aged rat hippocampus. And, it has been also shown that inflammation increased the production of DRiPs, which are preferentially degraded by the immunoproteasome (Seifert et al., 2010). All these data indicate that chronic inflammation provides a cellular environment prone to protein aggregation (Pintado et al., 2012; Gavilán et al., 2015; Pintado et al., 2017).

Most of the age-related alterations observed in cellular proteostasis are often reproduced in young animals following LPS injection. For example, LPS induced the expression of the immunoproteasome and decreased proteasomal activity leading to the accumulation of polyubiquitinated proteins in pyramidal neurons (Pintado et al., 2012). Also, LPS increased the content of hydrophobic peptides (Gavilán et al., 2009a), induced autophagic activation, activated the UPR, and decreased the expression of ERAD markers (Pintado et al., 2017). Finally, the combination of inflammation and proteasome inhibition in young rat hippocampus reduced the UPR activation and the expression of ERAD markers (Pintado et al.,
2017) and produced a similar degree of neurodegeneration to that observed in aged animals subjected only to proteasome inhibition (Gavilán et al., 2009b; Pintado et al., 2012).

All these data indicate that inflammation and proteostasis alteration should be considered as synergistic negative factors that might increase cell vulnerability in aging. This is especially relevant in the context of some age-related pathologies such as obesity, hypertension, diabetes, and neurodegenerative disorders, all of them characterized by oxidative stress and inflammation. However, having in mind the complexity in the reciprocal influences between inflammation and the different protein quality control systems, as well as the cell specificity of these interactions, further studies in the context of aging will be necessary to better understand the synergistic negative effects of these two processes.

\section{CONCLUSION}

The progressive and irreversible disruption of physiological functions, as a consequence of age-dependent systemic dysregulation, produces aging cell and whole-organism deterioration. Aging is a multifactorial process and here, I have reviewed how cellular proteostasis and inflammation become altered during aging (Figure 4). For example, chronic systemic diseases, 
recurrent infections, or metabolic disorders, might be factors promoting chronic inflammation throughout life, which in turn represent a hallmark of neurodegenerative disorders such as Alzheimer's and Parkinson's diseases. Inflammation and proteostasis regulate each other. This reciprocal regulation might be useful during acute stress situations to control the homeostatic response. However, during chronic inflammation and/or chronic proteostasis alteration, these two stressful situations might be reciprocally potentiated, increasing cell vulnerability.

Even though aging is a progressive and irreversible process, modulation of inflammation and oxidative stress might result in a slowdown of the cellular proteostasis affectation. Therefore, a healthy lifestyle is pivotal to reach successful aging. Promising preventive strategies such as healthy nutrition, and mainly, regular physical activity should be incorporated into our daily lifestyle, to prevent most of the age-related pathologies. For example, caloric restriction, without malnutrition, is the most powerful non-genetic intervention for extending longevity and healthspan in multiple animal models (Fontana et al., 2010). It has been found that caloric restriction reduced cellular senescence and mitochondrial dysfunction, as well as activated autophagy and promoted DNA repair (Fontana et al., 2018). Also, caloric restriction reversed the abnormal patterns of cell communication, and the excessive proinflammatory ligand-receptor interplay, observed during aging (Ma et al., 2020). In addition to caloric restriction, another promising dietary strategy for reducing oxidative damage and inflammation is intermittent fasting (Longo and Mattson, 2014).

\section{REFERENCES}

Aki, M., Shimbara, N., Takashina, M., Akiyama, K., Kagawa, S., Tamura, T., et al. (1994). Interferon- $\gamma$ Induces Different Subunit Organizations and Functional Diversity of Proteasomes1. J. Biochem. 115 (2), 257-269. doi:10.1093/ oxfordjournals.jbchem.a124327

Alladi, P. A., Mahadevan, A., Vijayalakshmi, K., Muthane, U., Shankar, S. K., and Raju, T. R. (2010). Ageing Enhances a-synuclein, Ubiquitin and Endoplasmic Reticular Stress Protein Expression in the Nigral Neurons of Asian Indians. Neurochem. Int. 57 (5), 530-539. doi:10.1016/ j.neuint.2010.06.018

Ambra, R., Mocchegiani, E., Giacconi, R., Canali, R., Rinna, A., Malavolta, M., et al. (2004). Characterization of the Hsp70 Response in Lymphoblasts from Aged and Centenarian Subjects and Differential Effects of In Vitro Zinc Supplementation. Exp. Gerontol. 39, 1475-1484. doi:10.1016/j.exger.2004.07.009

Amin-Wetzel, N., Saunders, R. A., Kamphuis, M. J., Rato, C., Preissler, S., Harding, H. P., et al. (2017). A J-Protein Co-chaperone Recruits BiP to Monomerize IRE1 and Repress the Unfolded Protein Response. Cell 171 (7), 1625-1637. doi:10.1016/j.cell.2017.10.040

Aragonès, G., Dasuri, K., Olukorede, O., Francisco, S. G., Renneburg, C., Kumsta, C., et al. (2020). Autophagic Receptor P62 Protects against Glycation-derived Toxicity and Enhances Viability. Aging Cell 19 (11), e13257. doi:10.1111/ acel. 13257

Arima, K., Kinoshita, A., Mishima, H., Kanazawa, N., Kaneko, T., Mizushima, T., et al. (2011). Proteasome Assembly Defect Due to a Proteasome Subunit Beta Type 8 (PSMB8) Mutation Causes the Autoinflammatory Disorder, NakajoNishimura Syndrome. Proc. Natl. Acad. Sci. 108 (36), 14914-14919. doi:10.1073/pnas.1106015108

Artal-Martinez de Narvajas, A., Gomez, T. S., Zhang, J.-S., Mann, A. O., Taoda, Y., Gorman, J. A., et al. (2013). Epigenetic Regulation of Autophagy by the
On the other hand, the regular practice of a physical activity is one of the most promising anti-aging strategies (RebeloMarques, et al., 2018). It is widely accepted that physical activity has positive effects on the aging immune system. Physical activity has anti-inflammatory properties (Gleeson et al., 2011), ameliorates metabolic health in older people (Pedersen, 2006), reduces inflammaging and immunosenescence (Weyh et al., 2020), and induces autophagy by modulating the IGF-1/AKT/mTOR, and AKT/ FOXO3A signaling pathways (Kim Y.,A. et al., 2013; Luo et al., 2013), among other benefits. Moreover, epidemiological studies have found that physical inactivity is associated with systemic low-grade inflammation (Parsons et al., 2017).

Although aging is an irreversible process, it can be modulated. Strategies combining diet and physical activity will allow us to reduce, at the molecular level, the most harmful effects of aging leading to disability and frailty.

\section{AUTHOR CONTRIBUTIONS}

The author confirms being the sole contributor of this work and has approved it for publication.

\section{FUNDING}

This work was supported by grants from the Junta de Andalucía to the research group CTS257-Aging and Neurodegeneration.

Methyltransferase G9a. Mol. Cel Biol. 33 (20), 3983-3993. doi:10.1128/ MCB.00813-13

Baek, S., H., and Kim, K., I. (2017). Epigenetic Control of Autophagy: Nuclear Events Gain More Attention. Mol. Cel. 65 (5), 781-785. doi:10.1016/ j.molcel.2016.12.027

Baraibar, M. A., and Friguet, B. (2012). Changes of the Proteasomal System during the Aging Process. Prog. Mol. Biol. Transl Sci. 109, 249-275. doi:10.1016/B9780-12-397863-9.00007-9

Bardag-Gorce, F., Farout, L., Veyrat-Durebex, C., Briand, Y., and Briand, M. (1999). Changes in 20S Proteasome Activity during Ageing of the LOU Rat. Mol. Biol. Rep. 26 (1-2), 89-93. doi:10.1023/a:1006968208077

Barrientos, R., M., Kitt, M., M., Watkins, L., R., and Maier, S., F. (2015). Neuroinflammation in the normal Aging hippocampus. Neuroscience 309, 84-99. doi:10.1016/j.neuroscience.2015.03.007

Behl, C. (2016). Breaking BAG: The Co-chaperone BAG3 in Health and Disease. Trends Pharmacol. Sci. 37 (8), 672-688. doi:10.1016/j.tips.2016.04.007

Bence, N., F., Sampat, R., M., and Kopito, R., R. (2001). Impairment of the Ubiquitin-Proteasome System by Protein Aggregation. Science 292 (5521), 1552-1555. doi:10.1126/science.292.5521.1552

Bergamini, E., Cavallini, G., Donati, A., and Gori, Z. (2004). The Role of Macroautophagy in the Ageing Process, Anti-ageing Intervention and AgeAssociated Diseases. Int. J. Biochem. Cel Biol. 36 (12), 2392-2404. doi:10.1016/ j.biocel.2004.05.007

Booth, L., N., and Brunet, A. (2016). The Aging Epigenome. Mol. Cel. 62 (5), 728-744. doi:10.1016/j.molcel.2016.05.013

Bourdenx, M., Martín-Segura, A., Scrivo, A., Rodriguez-Navarro, J., A., Kaushik, S., Tasset, I., et al. (2021). Chaperone-mediated Autophagy Prevents Collapse of the Neuronal Metastable Proteome. Cell 2021 (21), S0092-S8674. doi:10.1016/j.cell.2021.03.048

Braakman, I., and Hebert, D., N. (2013). Protein Folding in the Endoplasmic Reticulum. Cold Spring Harb Perspect. Biol. 5 (5), a013201. doi:10.1101/ cshperspect.a013201 
Brehm, A., and Krüger, E. (2015). Dysfunction in Protein Clearance by the Proteasome: Impact on Autoinflammatory Diseases. Semin. Immunopathol. 37, 323-333. doi:10.1007/s00281-015-0486-4

Brehme, M., Voisine, C., Rolland, T., Wachi, S., Soper, J. H., et al. (2014). A Chaperome Sub-network Safeguards Proteostasis in Aging and Neurodegenerative Disease. Cell Rep. 9 (3), 1135-1150. doi:10.1016/ j.celrep.2014.09.042

Breitschopf, K., Bengal, E., Ziv, T., Admon, A., and Ciechanover, A. (1998). A Novel Site for Ubiquitination: the N-Terminal Residue, and Not Internal Lysines of MyoD, Is Essential for Conjugation and Degradation of the Protein. EMBO J. 17 (20), 5964-5973. doi:10.1093/emboj/17.20.5964

Bulleid, N., J. (2012). Disulfide Bond Formation in the Mammalian Endoplasmic Reticulum. Cold Spring Harb Perspect. Biol. 4 (11), a013219. doi:10.1101/ cshperspect.a013219

Bulteau, A. L., Lundberg, K. C., Humphries, K. M., Sadek, H. A., Szweda, P. A., Friguet, B., et al. (2001). Oxidative Modification and Inactivation of the Proteasome during Coronary Occlusion/reperfusion. J. Biol. Chem. 276 (32), 30057-30063. doi:10.1074/jbc.M100142200

Bulteau, A., L., Petropoulos, I., and Friguet, B. (2000). Age-related Alterations of Proteasome Structure and Function in Aging Epidermis. Exp. Gerontol. 35 (67), 767-777. doi:10.1016/s0531-5565(00)00136-4

Bulteau, A., L., Szweda, L., I., and Friguet, B. (2002). Age-dependent Declines in Proteasome Activity in the Heart. Arch. Biochem. Biophys. 397 (2), 298-304. doi:10.1006/abbi.2001.2663

Cadwell, K., and Coscoy, L. (2005). Ubiquitination on Nonlysine Residues by a Viral E3 Ubiquitin Ligase. Science 309 (5731), 127-130. doi:10.1126/ science. 1110340

Carlsson, S., R., and Simonsen, A. (2015). Membrane Dynamics in Autophagosome Biogenesis. J. Cel Sci. 28 (2), 193-205. doi:10.1242/jcs.141036

Carrard, G., Dieu, M., Raes, M., Toussaint, O., and Friguet, B. (2003). Impact of Ageing on Proteasome Structure and Function in Human Lymphocytes. Int. J. Biochem. Cel Biol. 35 (5), 728-739. doi:10.1016/s1357-2725(02) 00356-4

Cascio, P., Hilton, C., Kisselev, A., F., Rock, K., L., and Goldberg, A., L. (2001). $26 \mathrm{~S}$ Proteasomes and Immunoproteasomes Produce Mainly N-Extended Versions of an Antigenic Peptide. EMBO J. 20 (10), 2357-2366. doi:10.1093/emboj/ 20.10.2357

Cecarini, V., Bonfili, L., Cuccioloni, M., Mozzicafreddo, M., Angeletti, M., Keller, J., N., et al. (2016). The fine-tuning of Proteolytic Pathways in Alzheimer's Disease. Cell Mol Life Sci. 73 (18), 3433-3451. doi:10.1007/s00018-016-2238-6

Chapiro, J., Claverol, S., Piette, F., Ma, W., Stroobant, V., Guillaume, B., et al. (2006). Destructive Cleavage of Antigenic Peptides Either by the Immunoproteasome or by the Standard Proteasome Results in Differential Antigen Presentation. J. Immunol. 15 (2), 1053-1061. doi:10.4049/ jimmunol.176.2.1053

Choi, C., H., Lee, B., H., Ahn, S., G., and Oh, S., H. (2012). Proteasome InhibitionInduced P38 MAPK/ERK Signaling Regulates Autophagy and Apoptosis through the Dual Phosphorylation of Glycogen Synthase Kinase $3 \beta$. Biochem. Biophys. Res. Commun. 418 (4), 759-764. doi:10.1016/ j.bbrc.2012.01.095

Chondrogianni, N., and Gonos, E., S. (2007). Overexpression of hUMP1/ POMP Proteasome Accessory Protein Enhances Proteasome Mediated Antioxidant Defence. Exp. Gerontol. 42 (9), 899-903. doi:10.1016/ j.exger.2007.01.012

Chondrogianni, N., Stratford, F., L., Trougakos, I., P., Friguet, B., Rivett, A., J., and Gonos, E., S. (2003). Central Role of the Proteasome in Senescence and Survival of Human Fibroblasts: Induction of a Senescence-like Phenotype upon its Inhibition and Resistance to Stress upon its Activation. J. Biol. Chem. 278 (30), 28026-28037. doi:10.1074/jbc.M301048200

Ciechanover, A., and Kwon, Y., T. (2017). Protein Quality Control by Molecular Chaperones in Neurodegeneration. Front. Neurosci. 11, 185. doi:10.3389/ fnins.2017.00185

Collins, G., A., and Goldberg, A., L. (2017). The Logic of the 26 S Proteasome. Cell 169 (5), 792-806. doi:10.1016/j.cell.2017.04.023

Conconi, M., Szweda, L. I., Levine, R., L., Stadtman, E., R., and Friguet, B. (1996). Age-related Decline of Rat Liver Multicatalytic Proteinase Activity and protection from Oxidative Inactivation by Heat-Shock Protein 90. Arch. Biochem. Biophys. 331 (2), 232-240. doi:10.1006/abbi.1996.0303
Conde, J., R., and Streit, W., J. (2006). Microglia in the Aging Brain. J. Neuropathol. Exp. Neurol. 65 (3), 199-203. doi:10.1097/01.jnen.0000202887.22082.63

Connor, A., M., Mahomed, N., Gandhi, R., Keystone, E., C., and Berger, S., A. (2012). TNFa Modulates Protein Degradation Pathways in Rheumatoid Arthritis Synovial Fibroblasts. Arthritis Res. Ther. 14 (2), R62. doi:10.1186/ $\operatorname{ar} 3778$

Crum, T., S., Gleixner, A., M., Posimo, J., M., Mason, D., M., Broeren, M., T., Heinemann, S., D., et al. (2015). Heat Shock Protein Responses to Aging and Proteotoxicity in the Olfactory Bulb. J. Neurochem. 133 (6), 780-794. doi:10.1111/jnc.13041

Cuervo, A., M., and Dice, J., F. (2000). Age-related Decline in Chaperone-Mediated Autophagy. J. Biol. Chem. 275 (40), 31505-31513. doi:10.1074/jbc.M002102200

Cuervo, A. M., and Wong, E. (2014). Chaperone-mediated Autophagy: Roles in Disease and Aging. Cell Res. 24 (1), 92-104. doi:10.1038/cr.2013.153

Danieli, A., and Martens, S. (2018). p62-mediated Phase Separation at the Intersection of the Ubiquitin-Proteasome System and Autophagy. J. Cel Sci. 131 (19), jcs214304. doi:10.1242/jcs.214304

Davies, K., J. (2001). Degradation of Oxidized Proteins by the 20S Proteasome. Biochimie. 83 (3-4), 301-310. doi:10.1016/s0300-9084(01)01250-0

de Jesus, A., A., Brehm, A., VanTries, R., Pillet, P., Parentelli, A., S., Montealegre Sanchez, G., A., et al. (2019). Novel Proteasome Assembly Chaperone Mutations in PSMG2/PAC2 Cause the Autoinflammatory Interferonopathy CANDLE/PRAAS4. J. Allergy Clin. Immunol. 143 (5), 1939-1943. doi:10.1016/ j.jaci.2018.12.1012

Deguchi, Y., Negoro, S., and Kishimoto, S. (1988). Age-related Changes of Heat Shock Protein Gene Transcription in Human Peripheral Blood Mononuclear Cells. Biochem. Biophys. Res. Commun. 157 (2), 580-584. doi:10.1016/s0006$291 x(88) 80289-4$

Demand, J., Alberti, S., Patterson, C., and Höhfeld, J. (2001). Cooperation of a Ubiquitin Domain Protein and an E3 Ubiquitin Ligase during Chaperone/ proteasome Coupling. Curr. Biol. 11 (20), 1569-1577. doi:10.1016/s09609822(01)00487-0

Demishtein, A., Fraiberg, M., Berko, D., Tirosh, B., Elazar, Z., and Navon, A. (2017). SQSTM1/p62-mediated Autophagy Compensates for Loss of Proteasome Polyubiquitin Recruiting Capacity. Autophagy. 13 (10), 1697-1708. doi:10.1080/15548627.2017.1356549

Dice, J., F. (1982). Altered Degradation of Proteins Microinjected into Senescent Human Fibroblasts. J. Biol. Chem. 257 (24), 14624-14627. doi:10.1016/s00219258(18)33324-6

Ding, W., X., Ni, H., M., Gao, W., Yoshimori, T., Stolz, D. B., et al. (2007). Linking of Autophagy to Ubiquitin-Proteasome System Is Important for the Regulation of Endoplasmic Reticulum Stress and Cell Viability. Am. J. Pathol. 171 (2), 513-524. doi:10.2353/ajpath.2007.070188

Ding, W., X., and Yin, X., M. (2008). Sorting, Recognition and Activation of the Misfolded Protein Degradation Pathways through Macroautophagy and the Proteasome. Autophagy. 4 (2), 141-150. doi:10.4161/auto.5190

Dong, L., Tan, C., W., Feng, P., J., Liu, F., B., Liu, D., X., Zhou, J., J., et al. (2021). Activation of TREM-1 Induces Endoplasmic Reticulum Stress through IRE-1a/ XBP-1s Pathway in Murine Macrophages. Mol. Immunol. 2021, 294-303. doi:10.1016/j.molimm.2021.04.023

Dong, S., Jia, C., Zhang, S., Fan, G., Li, Y., Shan, P., et al. (2013). The REG $\gamma$ Proteasome Regulates Hepatic Lipid Metabolism through Inhibition of Autophagy. Cell Metab. 18 (3), 380-391. doi:10.1016/j.cmet.2013.08.012

Eletto, D., Eletto, D., Dersh, D., Gidalevitz, T., and Argon, Y. (2014). Protein Disulfide Isomerase A6 Controls the Decay of IRE1 $\alpha$ Signaling via Disulfide-dependent Association. Mol. Cel. 53 (4), 562-576. doi:10.1016/j.molcel.2014.01.004

Erickson, R., R., Dunning, L., M., and Holtzman, J., L. (2006). The Effect of Aging on the Chaperone Concentrations in the Hepatic, Endoplasmic Reticulum of Male Rats: the Possible Role of Protein Misfolding Due to the Loss of Chaperones in the Decline in Physiological Function Seen with Age. J. Gerontol. A. Biol. Sci. Med. Sci. 61 (5), 435-443. doi:10.1093/gerona/61.5.435 Eskelinen, E., L., Illert, A., L., Tanaka, Y., Schwarzmann, G., Blanz, J., Von Figura, K., et al. (2002). Role of LAMP-2 in Lysosome Biogenesis and Autophagy. Mol. Biol. Cel. 13 (9), 3355-3368. doi:10.1091/mbc.e02-02-0114

Eskelinen, E., L., Schmidt, C., K., Neu, S., Willenborg, M., Fuertes, G., Salvador, N., et al. (2004). Disturbed Cholesterol Traffic but normal Proteolytic Function in LAMP-1/LAMP-2 Double-Deficient Fibroblasts. Mol. Biol. Cel. 15 (7), 3132-3145. doi:10.1091/mbc.e04-02-0103 
Esser, C., Alberti, S., and Höhfeld, J. (2004). Cooperation of Molecular Chaperones with the Ubiquitin/proteasome System. Biochim. Biophys. Acta. 1695 (1-3), 171-188. doi:10.1016/j.bbamcr.2004.09.020

Fargnoli, J., Kunisada, T., Fornace, A. J., Jr., Schneider, E., L., and Holbrook, N., J. (1990). Decreased Expression of Heat Shock Protein 70 mRNA and Protein after Heat Treatment in Cells of Aged Rats. P Natl. Acad. Sci. USA. 87, 846-850. doi:10.1073/pnas.87.2.846

Ferrington, D., A., Husom, A., D., and Thompson, L., V. (2005). Altered Proteasome Structure, Function and Oxidation in Aged Muscle. FASEB J. 19 (6), 644-646. doi:10.1096/fj.04-2578fje

Ferrington, D., A., and Kapphahn, R., J. (2004). Catalytic Site-specific Inhibition of the 20S Proteasome by 4-hydroxynonenal. FEBS Lett. 578 (3), 217-223. doi:10.1016/j.febslet.2004.11.003

Finley, D. (2009). Recognition and Processing of Ubiquitin-Protein Conjugates by the Proteasome. Annu. Rev. Biochem. 78, 477-513. doi:10.1146/ annurev.biochem.78.081507.101607

Fontana, L., Nehme, J., and Demaria, M. (2018). Caloric Restriction and Cellular Senescence. Mech. Ageing Dev. 176, 19-23. doi:10.1016/j.mad.2018.10.005

Fontana, L., Partridge, L., and Longo, V., D. (2010). Extending Healthy Life SpanFfrom Yeast to Humans. Science 328 (5976), 321-326. doi:10.1126/ science. 1172539

Frakes, A., E., and Dillin, A. (2017). The UPR(ER): Sensor and Coordinator of Organismal Homeostasis. Mol. Cel. 66 (6), 761-771. doi:10.1016/ j.molcel.2017.05.031

Franceschi, C., Bonafè, M., Valensin, S., Olivieri, F., De Luca, M., Ottaviani, E., et al. (2000). Inflamm-aging. An Evolutionary Perspective on Immunosenescence. Ann. N. Y Acad. Sci. 908, 244-254. doi:10.1111/j.1749-6632.2000.tb06651.x

Fujita, E., Kouroku, Y., Isoai, A., Kumagai, H., Misutani, A., Matsuda, C., et al. (2007). Two Endoplasmic Reticulum-Associated Degradation (ERAD) Systems for the Novel Variant of the Mutant Dysferlin: Ubiquitin/proteasome ERAD(I) and Autophagy/lysosome ERAD(II). Hum. Mol. Genet. 16 (6), 618-629. doi:10.1093/hmg/ddm002

Füllgrabe, J., Klionsky, D., J., and Joseph, B. (2014). The Return of the Nucleus: Transcriptional and Epigenetic Control of Autophagy. Nat. Rev. Mol. Cel Biol. 15 (1), 65-74. doi:10.1038/nrm3716

Füllgrabe, J., Lynch-Day, M. A., Heldring, N., Li, W., Struijk, R., et al. (2013). The Histone H4 Lysine 16 Acetyltransferase hMOF Regulates the Outcome of Autophagy. Nature 500 (7463), 468-471. doi:10.1038/nature12313

Gaczynska, M., Goldberg, A. L., Tanaka, K., Hendil, K., B., and Rock, K., L. (1996). Proteasome Subunits X and Y Alter Peptidase Activities in Opposite Ways to the Interferon-Gamma-Induced Subunits LMP2 and LMP7. J. Biol. Chem. 271 (29), 17275-17280. doi:10.1074/jbc.271.29.17275

Gaczynska, M., Rock, K., L., and Goldberg, A., L. (1993). $\gamma$-Interferon and Expression of MHC Genes Regulate Peptide Hydrolysis by Proteasomes. Nature 365 (6443), 264-267. doi:10.1038/365264a0

Galluzzi, L., Baehrecke, E. H., Ballabio, A., Boya, P., Bravo-San Pedro, J. M., Cecconi, F., et al. (2017). Molecular Definitions of Autophagy and Related Processes. EMBO J. 36 (13), 1811-1836. doi:10.15252/embj.201796697

Gamerdinger, M., Hajieva, P., Kaya, A. M., Wolfrum, U., Hartl, F. U., and Behl, C. (2009). Protein Quality Control during Aging Involves Recruitment of the Macroautophagy Pathway by BAG3. EMBO J. 28 (7), 889-901. doi:10.1038/ emboj.2009.29

Gavilán, E., Giráldez, S., Sánchez-Aguayo, I., Romero, F., Ruano, D., and Daza, P. (2013). Breast Cancer Cell Line MCF7 Escapes from G1/S Arrest Induced by Proteasome Inhibition through a GSK-3 $\beta$ Dependent Mechanism. Sci. Rep. 5, 10027. doi:10.1038/srep10027

Gavilán, E., Pintado, C., Gavilán, M. P., Daza, P., Sánchez-Aguayo, I., et al. (2015). Age-related Dysfunctions of the Autophagy Lysosomal Pathway in Hippocampal Pyramidal Neurons under Proteasome Stress. Neurobiol. Aging. 36 (5), 1953-1963. doi:10.1016/j.neurobiolaging.2015.02.025

Gavilán, M. P., Castaño, A., Torres, M., Portavella, M., Caballero, C., Jiménez, S., et al. (2009a). Age-related Increase in the Immunoproteasome Content in Rat hippocampus: Molecular and Functional Aspects. J. Neurochem. 108 (1), 260-272. doi:10.1111/j.1471-4159.2008.05762.x

Gavilán, M. P., Pintado, C., Gavilán, E., Jiménez, S., Ríos, R., et al. (2009b). Dysfunction of the Unfolded Protein Response Increases Neurodegeneration in Aged Rat hippocampus Following Proteasome Inhibition. Aging Cell 8 (6), 654-665. doi:10.1111/j.1474-9726.2009.00519.x
Gavilán, M. P., Pintado, C., Gavilán, E., García-Cuervo, L., M., Castaño, A., et al. (2012). Age-related Differences in the Dynamics of Hippocampal Proteasome Recovery. J. Neurochem. 123 (4), 635-644. doi:10.1111/j.14714159.2012.07932.x

Gavilán, M. P., Revilla, E., Pintado, C., Castaño, A., Vizuete, M., et al. (2007). Molecular and Cellular Characterization of the Age-Related Neuroinflammatory Processes Occurring in normal Rat hippocampus: Potential Relation with the Loss of Somatostatin GABAergic Neurons. J. Neurochem. 103 (3), 984-996. doi:10.1111/j.1471-4159.2007.04787.x

Ghosh, A., K., Mau, T., O’Brien, M., Garg, S., and Yung, R. (2016). Impaired Autophagy Activity Is Linked to Elevated ER-Stress and Inflammation in Aging Adipose Tissue. Aging (Albany NY). 8 (10), 2525-2537. doi:10.18632/ aging.101083

Giannini, C., Kloß, A., Gohlke, S., Mishto, M., Nicholson, T., P., Sheppard, P., W., et al. (2013). Poly-Ub-substrate-degradative Activity of 26S Proteasome Is Not Impaired in the Aging Rat Brain. PLoS One. 8 (5), e64042. doi:10.1371/ journal.pone.0064042

Gidalevitz, T., Stevens, F., and Argon, Y. (2013). Orchestration of Secretory Protein Folding by ER Chaperones. Biochim. Biophys. Acta. 1833 (11), 2410-2424. doi:10.1016/j.bbamcr.2013.03.007

Gleeson, M., Bishop, N., C., Stensel, D., J., Lindley, M., R., Mastana, S., S., and Nimmo, M., A. (2011). The Anti-inflammatory Effects of Exercise: Mechanisms and Implications for the Prevention and Treatment of Disease. Nat. Rev. Immunol. 11 (9), 607-615. doi:10.1038/nri3041

González-Polo, R., A., Boya, P., Pauleau, A., L., Jalil, A., Larochette, N., Souquère, S., et al. (2005). The Apoptosis/autophagy Paradox: Autophagic Vacuolization before Apoptotic Death. J. Cel Sci. 118 (Pt 14), 3091-3102. doi:10.1242/ jcs. 02447

Gregori, L., Hainfeld, J., F., Simon, M., N., and Goldgaber, D. (1997). Binding of Amyloid Beta Protein to the 20 S Proteasome. J. Biol. Chem. 272 (1), 58-62. doi:10.1074/jbc.272.1.58

Grune, T., Catalgol, B., Licht, A., Ermak, G., Pickering, A., M., Ngo, J., K., et al. (2011). HSP70 Mediates Dissociation and Reassociation of the 26S Proteasome during Adaptation to Oxidative Stress. Free Radic. Biol. Med. 51 (7), 1355-1364. doi:10.1016/j.freeradbiomed.2011.06.015

Grune, T., Jung, T., Merker, K., and Davies, K., J. (2004). Decreased Proteolysis Caused by Protein Aggregates, Inclusion Bodies, Plaques, Lipofuscin, Ceroid, and 'aggresomes' during Oxidative Stress, Aging, and Disease. Int. J. Biochem. Cel Biol. 36 (12), 2519-2530. doi:10.1016/ j.biocel.2004.04.020

Grune, T., Merker, K., Sandig, G., and Davies, K., J. (2003). Selective Degradation of Oxidatively Modified Protein Substrates by the Proteasome. Biochem. Biophys. Res. Commun. 305 (3), 709-718. doi:10.1016/s0006-291x(03)00809-x

Hampton, R., Y., Gardner, R., G., and Rine, J. (1996). Role of 26S Proteasome and HRD Genes in the Degradation of 3-Hydroxy-3-Methylglutaryl-CoA Reductase, an Integral Endoplasmic Reticulum Membrane Protein. Mol. Biol. Cel. 7 (12), 2029-2044. doi:10.1091/mbc.7.12.2029

Haratake, K., Sato, A., Tsuruta, F., and Chiba, T. (2016). KIAA0368-deficiency Affects Disassembly of 26S Proteasome under Oxidative Stress Condition. J. Biochem. 159 (6), 609-618. doi:10.1093/jb/mvw006

Hartl, F., U., Bracher, A., and Hayer-Hartl, M. (2011). Molecular Chaperones in Protein Folding and Proteostasis. Nature 475 (7356), 324-332. doi:10.1038/ nature 10317

He, C., and Klionsky, D., J. (2009). Regulation Mechanisms and Signaling Pathways of Autophagy. Аnnu. Rev. Genet. 43, 67-93. doi:10.1146/annurev-genet102808-114910

Hetz, C., and Papa, F., R. (2018). The Unfolded Protein Response and Cell Fate Control. Mol. Cel. 69 (2), 169-181. doi:10.1016/j.molcel.2017.06.017

Heydari, A., R., Takahashi, R., Gutsmann, A., You, S., and Richardson, A. (1994). Hsp70 and Aging. Experientia. 50 (11-12), 1092-1098. doi:10.1007/ BF01923466

Higa, A., Taouji, S., Lhomond, S., Jensen, D., Fernandez-Zapico, M., E., Simpson, J., C., et al. (2014). Endoplasmic Reticulum Stress-Activated Transcription Factor ATF6 $\alpha$ Requires the Disulfide Isomerase PDIA5 to Modulate Chemoresistance. Mol. Cel Biol. 34 (10), 1839-1849. doi:10.1128/MCB.01484-13

Ho, J., Yu, J., Wong, S., H., Zhang, L., Liu, X., Wong, W., T., et al. (2016). Autophagy in Sepsis: Degradation into Exhaustion?. Autophagy. 12 (7), 1073-1082. doi:10.1080/15548627.2016.1179410 
Höhn, A., Jung, T., Grimm, S., Catalgol, B., Weber, D., and Grune, T. (2011). Lipofuscin Inhibits the Proteasome by Binding to Surface Motifs. Free Radic. Biol. Med. 50 (5), 585-591. doi:10.1016/j.freeradbiomed.2010.12.011

Hu, P., Han, Z., Couvillon, A., D., Kaufman, R. J., and Exton, J., H. (2006). Autocrine Tumor Necrosis Factor Alpha Links Endoplasmic Reticulum Stress to the Membrane Death Receptor Pathway through IRE1alpha-Mediated NFkappaB Activation and Down-Regulation of TRAF2 Expression. Mol. Cell Biol. 26 (8), 3071-3084. doi:10.1128/MCB.26.8.3071-3084.2006

Husom, A., D., Peters, E., A., Kolling, E., A., Fugere, N., A., Thompson, L., V., and Ferrington, D., A. (2004). Altered Proteasome Function and Subunit Composition in Aged Muscle. Arch. Biochem. Biophys. 421 (1), 67-76. doi:10.1016/j.abb.2003.10.010

Hussain, S., G., and Ramaiah, K., V. (2007). Reduced eIF2alpha Phosphorylation and Increased Proapoptotic Proteins in Aging. Biochem. Biophys. Res. Commun. 355 (2), 365-370. doi:10.1016/j.bbrc.2007.01.156

Ishii, T., Sakurai, T., Usami, H., and Uchida, K. (2005). Oxidative Modification of Proteasome: Identification of an Oxidation-Sensitive Subunit in $26 \mathrm{~S}$ Proteasome. Biochemistry. 44 (42), 13893-13901. doi:10.1021/bi051336u

Jiang, S., Park, D., W., Gao, Y., Ravi, S., Darley-Usmar, V., Abraham, E., et al. (2015). Participation of Proteasome-Ubiquitin Protein Degradation in Autophagy and the Activation of AMP-Activated Protein Kinase. Cell Signal. 27 (6), 1186-1197. doi:10.1016/j.cellsig.2015.02.024

Jimenez-Guardeño, J., M., Apolonia, L., Betancor, G., and Malim, M., H. (2019). Immunoproteasome Activation Enables Human TRIM5a Restriction of HIV-1. Nat. Microbiol. 4 (6), 933-940. doi:10.1038/s41564-019-0402-0

Jung, T., and Grune, T. (2012). Structure of the Proteasome. Prog. Mol. Biol. Transl Sci. 109, 1-39. doi:10.1016/B978-0-12-397863-9.00001-8

Kageyama, S., Sou, Y., S., Uemura, T., Kametaka, S., Saito, T., Ishimura, R., et al. (2014). Proteasome Dysfunction Activates Autophagy and the Keap1-Nrf2 Pathway. J. Biol. Chem. 289 (36), 24944-24955. doi:10.1074/jbc.M114.580357

Kampinga, H. H., Hageman, J., Vos, M., J., Kubota, H., Tanguay, R., M., et al. (2009). Guidelines for the Nomenclature of the Human Heat Shock Proteins. Cell Stress Chaperones. 1, 105-111. doi:10.1007/s12192-008-0068-7

Kaneko, M., and Nomura, Y. (2003). ER Signaling in Unfolded Protein Response. Life Sci. 74 (2-3), 199-205. doi:10.1016/j.lfs.2003.09.007

Karim, M., R., Fisher, C., R., Kapphahn, R., J., Polanco, J., R., and Ferrington, D., A. (2020). Investigating AKT Activation and Autophagy in ImmunoproteasomeDeficient Retinal Cells. PLoS One. 15 (4), e0231212. doi:10.1371/ journal.pone.0231212

Katsuragi, Y., Ichimura, Y., and Komatsu, M. (2015). p62/SQSTM1 Functions as a Signaling Hub and an Autophagy Adaptor. FEBS J. 282 (24), 4672-4678. doi: $10.1111 /$ febs. 13540

Kaushik, S., and Cuervo, A., M. (2008). Chaperone-mediated Autophagy. Methods Mol. Biol. 445, 227-244. doi:10.1007/978-1-59745-157-4_15

Kaushik, S., and Cuervo, A., M. (2012). Chaperonesinautophagy. Pharmacol. Res. 66, 484-493. doi:10.1016/j.phrs.2012.10.002

Kaushik, S., Massey, A., C., and Cuervo, A., M. (2006). Lysosome Membrane Lipid Microdomains: Novel Regulators of Chaperone-Mediated Autophagy. EMBO J. 25 (17), 3921-3933. doi:10.1038/sj.emboj.7601283

Kaushik, S., Massey, A. C., Mizushima, N., and Cuervo, A., M. (2008). Constitutive Activation of Chaperone-Mediated Autophagy in Cells with Impaired Macroautophagy. Mol. Biol. Cel. 19 (5), 2179-2192. doi:10.1091/mbc.e07-11-1155

Keller, C., W., Fokken, C., Turville, S. G., Lunemann, A., Schmidt, J., et al. (2011). TNF- $\alpha$ Induces Macroautophagy and Regulates MHC Class II Expression in Human Skeletal Muscle Cells. J. Biol. Chem. 286 (5), 3970-3980. doi:10.1074/ jbc.M110.159392

Keller, J., N., Huang, F., F., and Markesbery, W., R. (2000a). Decreased Levels of Proteasome Activity and Proteasome Expression in Aging Spinal Cord. Neuroscience 98 (1), 149-156. doi:10.1016/s0306-4522(00)00067-1

Keller, J., N., Hanni, K., B., and Markesbery, W., R. (2000b). Possible Involvement of Proteasome Inhibition in Aging: Implications for Oxidative Stress. Mech. Ageing Dev. 113 (1), 61-70. doi:10.1016/s0047-6374(99)00101-3

Kettern, N., Dreiseidler, M., Tawo, R., and Höhfeld, J. (2010). Chaperone-assisted Degradation: Multiple Paths to Destruction. Biol. Chem. 391 (5), 481-489. doi:10.1515/BC.2010.058

Khalil, H., Tazi, M., Caution, K., Ahmed, A., Kanneganti, A., Assani, K., et al. (2016). Aging Is Associated with Hypermethylation of Autophagy Genes in
Macrophages. Epigenetics. 11 (5), 381-388. doi:10.1080/ 15592294.2016.1144007

Kiffin, R., Christian, C., Knecht, E., and Cuervo, A., M. (2004). Activation of Chaperone-Mediated Autophagy during Oxidative Stress. Mol. Biol. Cel. 15 (11), 4829-4840. doi:10.1091/mbc.e04-06-0477

Kiffin, R., Kaushik, S., Zeng, M., Bandyopadhyay, U., Zhang, C., Massey, A. C., et al. (2007). Altered Dynamics of the Lysosomal Receptor for ChaperoneMediated Autophagy with Age. J. Cel Sci. 120 (Pt 5), 782-791. doi:10.1242/ jcs. 001073

Kim, Y., A., Kim, Y., S., Oh, S., L., Kim, H., J., and Song, W. (2013). Autophagic Response to Exercise Training in Skeletal Muscle with Age. J. Physiol. Biochem. 69 (4), 697-705. doi:10.1007/s13105-013-0246-7

Kim, Y., E., Hipp, M., S., Bracher, A., Hayer-Hartl, M., and Hartl, F., U. (2013). Molecular Chaperone Functions in Protein Folding and Proteostasis. Annu. Rev. Biochem. 82, 323-355. doi:10.1146/annurev-biochem-060208-092442

Kitamura, A., Maekawa, Y., Uehara, H., Izumi, K., Kawachi, I., Nishizawa, M., et al. (2011). A Mutation in the Immunoproteasome Subunit PSMB8 Causes Autoinflammation and Lipodystrophy in Humans. J. Clin. Invest. 121 (10), 4150-4160. doi:10.1172/JCI58414

Kleizen, B., and Braakman, I. (2004). Protein Folding and Quality Control in the Endoplasmic Reticulum. Curr. Opin. Cel Biol. 16 (4), 343-349. doi:10.1016/ j.ceb.2004.06.012

Komander, D. (2009). The Emerging Complexity of Protein Ubiquitination. Biochem. Soc. Trans. 37, 937-953. doi:10.1042/BST0370937

Komatsu, M., Waguri, S., Chiba, T., Murata, S., Iwata, J., Tanida, I., et al. (2006). Loss of Autophagy in the central Nervous System Causes Neurodegeneration in Mice. Nature 441 (7095), 880-884. doi:10.1038/nature04723

Komatsu, M., Waguri, S., Ueno, T., Iwata, J., Murata, S., Tanida, I., et al. (2005). Impairment of Starvation-Induced and Constitutive Autophagy in Atg7Deficient Mice. J. Cel Biol. 169 (3), 425-434. doi:10.1083/jcb.200412022

Korolchuk, V., I., Menzies, F., M., and Rubinsztein, D., C. (2010). Mechanisms of Cross-Talk between the Ubiquitin-Proteasome and Autophagy-Lysosome Systems. FEBS Lett. 584 (7), 1393-1398. doi:10.1016/j.febslet.2009.12.047

Korolchuk, V. I., Mansilla, A., Menzies, F., M., and Rubinsztein, D., C. (2009). Autophagy Inhibition Compromises Degradation of Ubiquitin-Proteasome Pathway Substrates. Mol. Cel. 33 (4), 517-527. doi:10.1016/j.molcel.2009.01.021

Korovila, I., Hugo, M., Castro, J. P., Weber, D., Höhn, A., et al. (2017). Proteostasis, Oxidative Stress and Aging. Redox Biol. 13, 550-567. doi:10.1016/ j.redox.2017.07.008

Kors, S., Geijtenbeek, K., Reits, E., and Schipper-Krom, S. (2019). Regulation of Proteasome Activity by (Post-)transcriptional Mechanisms. Front. Mol. Biosci. 6, 48. doi:10.3389/fmolb.2019.00048

Kranz, P., Neumann, F., Wolf, A., Classen, F., Pompsch, M., Ocklenburg, T., et al. (2017). PDI Is an Essential Redox-Sensitive Activator of PERK during the Unfolded Protein Response (UPR). Cell Death Dis. 8 (8), e2986. doi:10.1038/ cddis.2017.369

Kroemer, G., Mariño, G., and Levine, B. (2010). Autophagy and the Integrated Stress Response. Mol. Cel. 40 (2), 280-293. doi:10.1016/j.molcel.2010.09.023

Kyrychenko, V. O., Nagibin, V. S., Tumanovska, L. V., Pashevin, D. O., Gurianova, V. L., Moibenko, A. A., et al. (2014). Knockdown of PSMB7 Induces Autophagy in Cardiomyocyte Cultures: Possible Role in Endoplasmic Reticulum Stress. Pathobiology. 81 (1), 8-14. doi:10.1159/000350704

Lapierre, L., R., Kumsta, C., Sandri, M., Ballabio, A., and Hansen, M. (2015). Transcriptional and Epigenetic Regulation of Autophagy in Aging. Autophagy. 11 (6), 867-880. doi:10.1080/15548627.2015.1034410

Lee, C., K., Klopp, R., G., Weindruch, R., and Prolla, T., A. (1999). Gene Expression Profile of Aging and its Retardation by Caloric Restriction. Science 285 (5432), 1390-1393. doi:10.1126/science.285.5432.1390

Lee, C. K., Weindruch, R., and Prolla, T. A. (2000). Gene-expression Profile of the Ageing Brain in Mice. Nat. Genet. 25, 294-297. doi:10.1038/77046

Lee, J., Giordano, S., and Zhang, J. (2012). Autophagy, Mitochondria and Oxidative Stress: Cross-Talk and Redox Signalling. Biochem. J. 441 (2), 523-540. doi:10.1042/BJ20111451

Lefaki, M., Papaevgeniou, N., and Chondrogianni, N. (2017). Redox Regulation of Proteasome Function. Redox Biol. 13, 452-458. doi:10.1016/ j.redox.2017.07.005

Lipinski, M., M., Zheng, B., Lu, T., Yan, Z., Py, B. F., et al. (2010). Genome-wide Analysis Reveals Mechanisms Modulating Autophagy in normal Brain Aging 
and in Alzheimer's Disease. Proc. Natl. Acad. Sci. U S A. 107 (32), 14164-14169. doi:10.1073/pnas.1009485107

Liu, W. J., Ye, L., Huang, W., F., Guo, L., J., Xu, Z., G., et al. (2016). p62 Links the Autophagy Pathway and the Ubiqutin-Proteasome System upon Ubiquitinated Protein Degradation. Cell Mol Biol Lett. 21, 29. doi:10.1186/ s11658-016-0031-z

Liu, X., D., Ko, S., Xu, Y., Fattah, E., A., Xiang, Q., Jagannath, C., et al. (2012). Transient Aggregation of Ubiquitinated Proteins Is a Cytosolic Unfolded Protein Response to Inflammation and Endoplasmic Reticulum Stress. J. Biol. Chem. 287 (23), 19687-19698. doi:10.1074/jbc.M112.350934

Liu, Y., Ramot, Y., Torrelo, A., Paller, A. S., Si, N., et al. (2012). Mutations in Proteasome Subunit $\beta$ Type 8 Cause Chronic Atypical Neutrophilic Dermatosis with Lipodystrophy and Elevated Temperature with Evidence of Genetic and Phenotypic Heterogeneity. Arthritis Rheum. 64, 895-907. doi:10.1002/ art.33368

Livnat-Levanon, N., Kevei, É., Kleifeld, O., Krutauz, D., Segref, A., Rinaldi, T., et al. (2014). Reversible 26S Proteasome Disassembly upon Mitochondrial Stress. Cel Rep. 7 (5), 1371-1380. doi:10.1016/j.celrep.2014.04.030

Longo, V., D., and Mattson, M., P. (2014). Fasting: Molecular Mechanisms and Clinical Applications. Cel Metab. 19 (2), 181-192. doi:10.1016/ j.cmet.2013.12.008

López-Otin, C., Blasco, M., A., Partridge, L., Serrano, M., and Kroemer, G. (2013). The Hallmarks of Aging. Cell 153 (6), 1194-1217. doi:10.1016/j.cell.2013.05.039

Lu, T., Pan, Y., Kao, S. Y., Li, C., Kohane, I., et al. (2004). Gene Regulation and DNA Damage in the Ageing Human Brain. Nature 429, 883-891. doi:10.1038/ nature02661

Luders, J., Demand, J., and Höhfeld, J. (2000). The Ubiquitin-Related BAG-1 Provides a Link between the Molecular Chaperones Hsc70/Hsp70 and the Proteasome. J. Biol. Chem. 275 (7), 4613-4617. doi:10.1074/jbc.275.7.4613

Luo, L., Lu, A., M., Wang, Y., Hong, A., Chen, Y., Hu, J., et al. (2013). Chronic Resistance Training Activates Autophagy and Reduces Apoptosis of Muscle Cells by Modulating IGF-1 and its Receptors, Akt/mTOR and Akt/FOXO3a Signaling in Aged Rats. Exp. Gerontol. 48 (4), 427-436. doi:10.1016/ j.exger.2013.02.009

Ma, S., Sun, S., Geng, L., Song, M., Wang, W., Ye, Y., et al. (2020). Caloric Restriction Reprograms the Single-Cell Transcriptional Landscape of Rattus Norvegicus Aging. Cell 180 (5), 984-1001. doi:10.1016/j.cell.2020.02.008

Margariti, A., Li, H., Chen, T., Martin, D., Vizcay-Barrena, G., Alam, S., et al. (2013). XBP1 mRNA Splicing Triggers an Autophagic Response in Endothelial Cells through BECLIN-1 Transcriptional Activation. J. Biol. Chem. 288 (2), 859-872. doi:10.1074/jbc10.1074/jbc.m112.412783

Martinez-Vicente, M., Sovak, G., and Cuervo, A., M. (2005). Protein Degradation and Aging. Exp. Gerontol. 40 (8-9), 622-633. doi:10.1016/j.exger.2005.07.005

Martinon, F., Chen, X., Lee, A. H., and Glimcher, L. H. (2010). TLR Activation of the Transcription Factor XBP1 Regulates Innate Immune Responses in Macrophages. Nat. Immunol. 11 (5), 411-418. doi:10.1038/ni.1857

Massey, A. C., Kaushik, S., Sovak, G., Kiffin, R., and Cuervo, A. M. (2006). Consequences of the Selective Blockage of Chaperone-Mediated Autophagy. Proc. Natl. Acad. Sci. U S A. 103 (15), 5805-5810. doi:10.1073/pnas.0507436103

Mayer, M., P., and Gierasch, L., M. (2019). Recent Advances in the Structural and Mechanistic Aspects of Hsp70 Molecular Chaperones. J. Biol. Chem. 294, 2085-2097. doi:10.1074/jbc.REV118.002810

McDonough, H., and Patterson, C. (2003). CHIP: a Link between the Chaperone and Proteasome Systems. Cell Stress Chaperones. 8 (4), 303-308. doi:10.1379/ 1466-1268(2003)008<0303:calbtc $>2.0 . c 0 ; 2$

Merker, K., Sitte, N., and Grune, T. (2000). Hydrogen Peroxide-Mediated Protein Oxidation in Young and Old Human MRC-5 Fibroblasts. Arch. Biochem. Biophys. 375 (1), 50-54. doi:10.1006/abbi.1999.1657

Meusser, B., Hirsch, C., Jarosch, E., and Sommer, T. (2005). ERAD: the Long Road to Destruction. Nat. Cel Biol. 7 (8), 766-772. doi:10.1038/ncb0805-766

Mijaljica, D., Prescott, M., and Devenish, R. J. (2011). Microautophagy in Mammalian Cells: Revisiting a 40-Year-Old Conundrum. Autophagy. 7 (7), 673-682. doi:10.4161/auto.7.7.14733

Min, H., Xu, M., Chen, Z., R., Zhou, J., D., Huang, M., Zheng, K., et al. (2014). Bortezomib Induces Protective Autophagy through AMP-Activated Protein Kinase Activation in Cultured Pancreatic and Colorectal Cancer Cells. Cancer Chemother. Pharmacol. 74 (1), 167-176. doi:10.1007/s00280-014-2451-7
Minciullo, P., L., Catalano, A., Mandraffino, G., Casciaro, M., Crucitti, A., Maltese, G., et al. (2012). Inflammaging and Anti-inflammaging: The Role of Cytokines in Extreme Longevity. Arch. Immunol. Ther. Exp. (Warsz). 64 (2), 111-126. doi:10.1007/s00005-015-0377-3

Mishto, M., Bellavista, E., Santoro, A., Stolzing, A., Ligorio, C., Nacmias, B., et al. (2006). Immunoproteasome and LMP2 Polymorphism in Aged and Alzheimer's Disease Brains. Neurobiol. Aging. 27 (1), 54-66. doi:10.1016/ j.neurobiolaging.2004.12.004

Mizushima, N., Levine, B., Cuervo, A., M., and Klionsky, D., J. (2008). Autophagy Fights Disease through Cellular Self-Digestion. Nature 451 (7182), 1069-1075. doi:10.1038/nature06639

Moebius, J., van den Broek, M., Groettrup, M., and Basler, M. (2010). Immunoproteasomes Are Essential for Survival and Expansion of $\mathrm{T}$ Cells in Virus-Infected Mice. Eur. J. Immunol. 40 (12), 3439-3449. doi:10.1002/ eji.201040620

Moritz, K., E., McCormack, N., M., Abera, M., B., Viollet, C., Yauger, Y., J., Sukumar, G., et al. (2017). The Role of the Immunoproteasome in Interferon$\gamma$-Mediated Microglial Activation. Sci. Rep. 7 (1), 9365. doi:10.1038/s41598017-09715-y

Muchamuel, T., Basler, M., Aujay, M. A., Suzuki, E., Kalim, K., W., et al. (2009). A Selective Inhibitor of the Immunoproteasome Subunit LMP7 Blocks Cytokine Production and Attenuates Progression of Experimental Arthritis. Nat. Med. 15 (7), 781-787. doi:10.1038/nm.1978

Myeku, N., and Figueiredo-Pereira, M., E. (2011). Dynamics of the Degradation of Ubiquitinated Proteins by Proteasomes and Autophagy: Association with Sequestosome 1/p62. J. Biol. Chem. 286 (25), 22426-22440. doi:10.1074/ jbc.M110.149252

Naidoo, N., Ferber, M., Master, M., Zhu, Y., and Pack, A., I. (2008). Aging Impairs the Unfolded Protein Response to Sleep Deprivation and Leads to Proapoptotic Signaling. J. Neurosci. 28 (26), 6539-6548. doi:10.1523/JNEUROSCI.568507.2008

Nitta, Y., Abe, K., Aoki, M., Ohno, I., and Isoyama, S. (1994). Diminished Heat Shock Protein 70 mRNA Induction in Aged Rat Hearts after Ischemia. Am. J. Physiol. 267 (5 Pt 2), H1795-H1803. doi:10.1152/ ajpheart.1994.267.5.H1795

Norden, D. M., and Godbout, J. P. (2013). Microglia of the Aged Brain: Primed to Be Activated and Resistant to Regulation. Neuropathol. Appl. Neurobiol. 39 (1), 19-34. doi:10.1111/j.1365-2990.2012.01306.x

Nuss, J., E., Choksi, K., B., DeFord, J., H., and Papaconstantinou, J. (2008). Decreased Enzyme Activities of Chaperones PDI and BiP in Aged Mouse Livers. Biochem. Biophys. Res. Commun. 365 (2), 355-361. doi:10.1016/ j.bbrc.2007.10.194

Oddo, S. (2008). The Ubiquitin-Proteasome System in Alzheimer's Disease. J. Cel Mol Med. 12 (2), 363-373. doi:10.1111/j.1582-4934.2008.00276.x

Oka, O., B., and Bulleid, N., J. (2013). Forming Disulfides in the Endoplasmic Reticulum. Biochim. Biophys. Acta. 1833 (11), 2425-2429. doi:10.1016/ j.bbamcr.2013.02.007

Opitz, E., Koch, A., Klingel, K., Schmidt, F., Prokop, S., Rahnefeld, A., et al. (2011). Impairment of Immunoproteasome Function by $\beta 5 \mathrm{i} / \mathrm{LMP} 7$ Subunit Deficiency Results in Severe Enterovirus Myocarditis. Plos Pathog. 7, e1002233. doi:10.1371/journal.ppat.1002233

Ott, C., König, J., Höhn, A., Jung, T., and Grune, T. (2016). Macroautophagy Is Impaired in Old Murine Brain Tissue as Well as in Senescent Human Fibroblasts. Redox Biol. 10, 266-273. doi:10.1016/j.redox.2016.10.015

Pan, B., Li, J., Parajuli, N., Tian, Z., Wu, P., Lewno, M. T., et al. (2020). The Calcineurin-TFEB-P62 Pathway Mediates the Activation of Cardiac Macroautophagy by Proteasomal Malfunction. Circ. Res. 127 (4), 502-518. doi:10.1161/CIRCRESAHA.119.316007

Park, C., and Cuervo, A., M. (2013). Selective Autophagy: Talking with the UPS. Cell Biochem Biophys. 67 (1), 3-13. doi:10.1007/s12013-013-9623-7

Parsons, T., J., Sartini, C., Welsh, P., Sattar, N., Ash, S., Lennon, L., T., et al. (2017). Physical Activity, Sedentary Behavior, and Inflammatory and Hemostatic Markers in Men. Med. Sci. Sports Exerc. 49 (3), 459-465. doi:10.1249/ MSS.0000000000001113

Paz Gavilán, M., Vela, J., Castaño, A., Ramos, B., del Río, J. C., et al. (2006). Cellular Environment Facilitates Protein Accumulation in Aged Rat hippocampus. Neurobiol. Aging. 27 (7), 973-982. doi:10.1016/j.neurobiolaging.2005.05.010 
Pedersen, B., K. (2006). The Anti-inflammatory Effect of Exercise: its Role in Diabetes and Cardiovascular Disease Control. Essays Biochem. 42, 105-117. doi:10.1042/bse 0420105

Petropoulos, I., Conconi, M., Wang, X., Hoenel, B., Brégégère, F., Milner, Y., et al. (2000). Increase of Oxidatively Modified Protein Is Associated with a Decrease of Proteasome Activity and Content in Aging Epidermal Cells. J. Gerontol. A. Biol. Sci. Med. Sci. 55 (5), B220-B227. doi:10.1093/gerona/55.5.b220

Pickart, C., M., and Cohen, R., E. (2004). Proteasomes and Their Kin: Proteases in the Machine Age. Nat. Rev. Mol. Cel Biol. 5 (3), 177-187. doi:10.1038/nrm1336

Pickering, A., M., Koop, A., L., Teoh, C., Y., Ermak, G., Grune, T., and Davies, K., J. (2010). The Immunoproteasome, the $20 \mathrm{~S}$ Proteasome and the PA28a $\beta$ Proteasome Regulator Are Oxidative-Stress-Adaptive Proteolytic Complexes. Biochem. J. 432 (3), 585-594. doi:10.1042/BJ20100878

Pintado, C., Gavilán, M. P., Gavilán, E., García-Cuervo, L., Gutierrez, A., et al. (2012). Lipopolysaccharide-induced Neuroinflammation Leads to the Accumulation of Ubiquitinated Proteins and Increases Susceptibility to Neurodegeneration Induced by Proteasome Inhibition in Rat hippocampus. J. Neuroinflammation. 4 (9), 87. doi:10.1186/1742-2094-9-87

Pintado, C., Macías, S., Domínguez-Martín, H., Castaño, A., and Ruano, D. (2017). Neuroinflammation Alters Cellular Proteostasis by Producing Endoplasmic Reticulum Stress, Autophagy Activation and Disrupting ERAD Activation. Sci. Rep. 7 (1), 8100. doi:10.1038/s41598-017-08722-3

Poli, M. C., Ebstein, F., Nicholas, S., K., de Guzman, M., M., Forbes, L., R., et al. (2018). Heterozygous Truncating Variants in POMP Escape NonsenseMediated Decay and Cause a Unique Immune Dysregulatory Syndrome. Am. J. Hum. Genet. 102 (6), 1126-1142. doi:10.1016/j.ajhg.2018.04.010

Rabek, J., P., Boylston, W. H., 3rd, and Papaconstantinou, J. (2003). Carbonylation of ER Chaperone Proteins in Aged Mouse Liver. Biochem. Biophys. Res. Commun. 305 (3), 566-572. doi:10.1016/s0006-291x(03)00826-x

Radák, Z., Takahashi, R., Kumiyama, A., Nakamoto, H., Ohno, H., Ookawara, T., et al. (2002). Effect of Aging and Late Onset Dietary Restriction on Antioxidant Enzymes and Proteasome Activities, and Protein Carbonylation of Rat Skeletal Muscle and Tendon. Exp. Gerontol. 37 (12), 1423-1430. doi:10.1016/s05315565(02)00116-x

Raynes, R., Pomatto, L., C., and Davies, K., J. (2016). Degradation of Oxidized Proteins by the Proteasome: Distinguishing between the 20S, 26S, and Immunoproteasome Proteolytic Pathways. Mol. Aspects Med. 50, 41-55. doi:10.1016/j.mam.2016.05.001

Rebelo-Marques, A., De Sousa Lages, A., Andrade, R., Ribeiro, C., F., Mota-Pinto, A., Carrilho, F., et al. (2018). Aging Hallmarks: The Benefits of Physical Exercise. Front. Endocrinol. (Lausanne). 9, 258. doi:10.3389/fendo.2018.00258

Rechsteiner, M., and Hill, C., P. (2005). Mobilizing the Proteolytic Machine: Cell Biological Roles of Proteasome Activators and Inhibitors. Trends Cel Biol. 15, 27-33. doi:10.1016/j.tcb.2004.11.003

Reinheckel, T., Sitte, N., Ullrich, O., Kuckelkorn, U., Davies, K., J., and Grune, T. (1998). Comparative Resistance of the 20S and 26S Proteasome to Oxidative Stress. Biochem. J. 335 (Pt 3Pt 3), 637-642. doi:10.1042/bj3350637

Reinheckel, T., Ullrich, O., Sitte, N., and Grune, T. (2000). Differential Impairment of 20S and 26S Proteasome Activities in Human Hematopoietic K562 Cells during Oxidative Stress. Arch. Biochem. Biophys. 377 (1), 65-68. doi:10.1006/ abbi. 2000.1717

Rivett, A., J., Bose, S., Brooks, P., and Broadfoot, K., I. (2001). Regulation of Proteasome Complexes by Gamma-Interferon and Phosphorylation. Biochimie. 83 (3-4), 363-366. doi:10.1016/s0300-9084(01)01249-4

Rodríguez-Muela, N., Koga, H., García-Ledo, L., de la Villa, P., de la Rosa, E., J., Cuervo, A., et al. (2013). Balance between Autophagic Pathways Preserves Retinal Homeostasis. Aging Cell 12 (3), 478-488. doi:10.1111/acel.12072

Rodriguez-Navarro, J., A., Kaushik, S., Koga, H., Dall'Armi, C., Shui, G., Wenk, M., R., et al. (2012). Inhibitory Effect of Dietary Lipids on Chaperone-Mediated Autophagy. Proc. Natl. Acad. Sci. U S A. 109 (12), E705-E714. doi:10.1073/ pnas.1113036109

Rogov, V., Dötsch, V., Johansen, T., and Kirkin, V. (2014). Interactions between Autophagy Receptors and Ubiquitin-like Proteins Form the Molecular Basis for Selective Autophagy. Mol. Cel. 53 (2), 167-178. doi:10.1016/ j.molcel.2013.12.014

Rottenberg, H., and Hoek, J., B. (2017). The Path from Mitochondrial ROS to Aging Runs through the Mitochondrial Permeability Transition Pore. Aging Cell 16 (5), 943-955. doi:10.1111/acel.12650
Rui, Y., N., Xu, Z., Chen, Z., and Zhang, S. (2015). The GST-BHMT Assay Reveals a Distinct Mechanism Underlying Proteasome Inhibition-Induced Macroautophagy in Mammalian Cells. Autophagy. 11 (5), 812-832. doi:10.1080/15548627.2015.1034402

Salganik, M., Sergeyev, V. G., Shinde, V., Meyers, C., A., Gorbatyuk, M., S., et al. (2015). The Loss of Glucose-Regulated Protein 78 (GRP78) during normal Aging or from siRNA Knockdown Augments Human Alpha-Synuclein ( $\alpha$-Syn) Toxicity to Rat Nigral Neurons. Neurobiol. Aging. 36 (6), 2213-2223. doi:10.1016/j.neurobiolaging.2015.02.018

Salminen, A., Kauppinen, A., Suuronen, T., Kaarniranta, K., and Ojala, J. (2009). ER Stress in Alzheimer's Disease: a Novel Neuronal Trigger for Inflammation and Alzheimer's Pathology. J. Neuroinflammation. 6, 41. doi:10.1186/17422094-6-41

Samant, R., S., Livingston, C., M., Sontag, E., M., and Frydman, J. (2018). Distinct Proteostasis Circuits Cooperate in Nuclear and Cytoplasmic Protein Quality Control. Nature 563 (7731), 407-411. doi:10.1038/s41586-018-0678-x

Santin, Y., Sicard, P., Vigneron, F., Guilbeau-Frugier, C., Dutaur, M., Lairez, O., et al. (2016). Oxidative Stress by Monoamine Oxidase-A Impairs Transcription Factor EB Activation and Autophagosome Clearance, Leading to Cardiomyocyte Necrosis and Heart Failure. Antioxid. Redox Signal. 25 (1), 10-27. doi:10.1089/ars.2015.6522

Sarrabay, G., Méchin, D., Salhi, A., Boursier, G., Rittore, C., Crow, Y., et al. (2020). PSMB10, the Last Immunoproteasome Gene Missing for PRAAS. J. Allergy Clin. Immunol. 145 (3), 1015-1017. doi:10.1016/ j.jaci.2019.11.024

Scheinert, R., B., Asokan, A., Rani, A., Kumar, A., Foster, T., C., and Ormerod, B., K. (2015). Some Hormone, Cytokine and Chemokine Levels that Change across Lifespan Vary by Cognitive Status in Male Fischer 344 Rats. Brain Behav. Immun. 49, 216-232. doi:10.1016/j.bbi.2015.06.005

Scherz-Shouval, R., and Elazar, Z. (2007). ROS, Mitochondria and the Regulation of Autophagy. Trends Cel Biol 17 (9), 422-427. doi:10.1016/j.tcb.2007.07.009

Schneider, J. L., Villarroya, J., Diaz-Carretero, A., Patel, B., Urbanska, A., et al. (2015). Loss of Hepatic Chaperone-Mediated Autophagy Accelerates Proteostasis Failure in Aging. Aging Cell 14 (2), 249-264. doi:10.1111/ acel. 12310

Scialo, F., Fernández-Ayala, D. J., and Sanz, A. (2017). Role of Mitochondrial Reverse Electron Transport in ROS Signaling: Potential Roles in Health and Disease. Front. Physiol. 8, 428. doi:10.3389/fphys.2017.00428

Seifert, U., Bialy, L. P., Ebstein, F., Bech-Otschir, D., Voigt, A., et al. (2010), Immunoproteasomes Preserve Protein Homeostasis upon Interferon-Induced Oxidative Stress. Cell 142 (4), 613-624. doi:10.1016/j.cell.2010.07.036

Selimovic, D., Porzig, B. B., El-Khattouti, A., Badura, H., E., Ahmad, M., et al. (2013). Bortezomib/proteasome Inhibitor Triggers Both Apoptosis and Autophagy-dependent Pathways in Melanoma Cells. Cel Signal. 25 (1), 308-318. doi:10.1016/j.cellsig.2012.10.004

Sepulveda, D., Rojas-Rivera, D., Rodríguez, D., A., Groenendyk, J., Köhler, A., Lebeaupin, C., et al. (2018). Interactome Screening Identifies the ER Luminal Chaperone Hsp47 as a Regulator of the Unfolded Protein Response Transducer IRE1a. Mol. Cel. 69 (2), 238-252. doi:10.1016/j.molcel.2017.12.028

Shang, F., and Taylor, A. (1995). Oxidative Stress and Recovery from Oxidative Stress Are Associated with Altered Ubiquitin Conjugating and Proteolytic Activities in Bovine Lens Epithelial Cells. Biochem. J. 307 (Pt 1), 297-303. doi:10.1042/bj3070297

Sheng, J., G., Mrak, R., E., and Griffin, W. (1998). Enlarged and Phagocytic, but Not Primed, Interleukin-1 a-immunoreactive Microglia Increase with Age in normal Human Brain. Acta Neuropathol. 95 (3), 229-234. doi:10.1007/ s004010050792

Shimizu, Y., Okuda-Shimizu, Y., and Hendershot, L. M. (2010). Ubiquitylation of an ERAD Substrate Occurs on Multiple Types of Amino Acids. Mol. Cel. 40 (6), 917-926. doi:10.1016/j.molcel.2010.11.033

Shin, H., J., Kim, H., Oh, S., Lee, J. G., Kee, M., et al. (2016). AMPK-SKP2-CARM1 Signalling cascade in Transcriptional Regulation of Autophagy. Nature 534 (7608), 553-557. doi:10.1038/nature18014

Silva, G., M., Netto, L., E., Simões, V., Santos, L., F., Gozzo, F., C., Demasi, M., A., et al. (2012). Redox Control of 20S Proteasome Gating. Antioxid. Redox Signal. 16 (11), 1183-1194. doi:10.1089/ars.2011.4210

Singh, R., Kølvraa, S., Bross, P., Jensen, U. B., Gregersen, N., et al. (2006). Reduced Heat Shock Response in Human Mononuclear Cells during Aging and its 
Association with Polymorphisms in HSP70 Genes. Cell Stress Chaperones 11 (3), 208-215. doi:10.1379/csc-184r.1

Squier, T., C. (2001). Oxidative Stress and Protein Aggregation during Biological Aging. Exp. Gerontol. 36 (9), 1539-1550. doi:10.1016/s0531-5565(01)00139-5

Strehl, B., Seifert, U., Krüger, E., Heink, S., Kuckelkorn, U., and Kloetzel, P., M. (2005). Interferon-gamma, the Functional Plasticity of the UbiquitinProteasome System, and MHC Class I Antigen Processing. Immunol. Rev. 207, 19-30. doi:10.1111/j.0105-2896.2005.00308.x

Stürner, E., and Behl, C. (2017). The Role of the Multifunctional BAG3 Protein in Cellular Protein Quality Control and in Disease. Front. Mol. Neurosci. 10, 177. doi:10.3389/fnmol.2017.00177

Sun, S., Shi, G., Sha, H., Ji, Y., Han, X., Shu, X., et al. (2015). IRE1a Is an Endogenous Substrate of Endoplasmic-Reticulum-Associated Degradation. Nat. Cell Biol. 17 (12), 1546-1555. doi:10.1038/ncb3266

Tan, L., Register, T., C., and Yammani, R., R. (2020). Age-Related Decline in Expression of Molecular Chaperones Induces Endoplasmic Reticulum Stress and Chondrocyte Apoptosis in Articular Cartilage. Aging Dis. 11 (5), 1091-1102. doi:10.14336/AD.2019.1130

Tanaka, K. (2009). The Proteasome: Overview of Structure and Functions. Proc. Jpn. Acad. Ser. B Phys. Biol. Sci. 85 (1), 12-36. doi:10.2183/pjab.85.12

Tanaka, Y., Guhde, G., Suter, A., Eskelinen, E., L., Hartmann, D., LüllmannRauch, R., et al. (2000). Accumulation of Autophagic Vacuoles and Cardiomyopathy in LAMP-2-Deficient Mice. Nature 406 (6798), 902-906. doi:10.1038/35022595

Taneike, M., Yamaguchi, O., Nakai, A., Hikoso, S., Takeda, T., Mizote, I., et al. (2010). Inhibition of Autophagy in the Heart Induces Age-Related Cardiomyopathy. Autophagy. 6 (5), 600-606. doi:10.4161/auto.6.5.11947

Terman, A. (1995). The Effect of Age on Formation and Elimination of Autophagic Vacuoles in Mouse Hepatocytes. Gerontology 41 (Suppl. 2), 319-326. doi:10.1159/000213753

Tian, P., G., Jiang, Z., X., Li, J., H., Zhou, Z., and Zhang, Q., H. (2015). Spliced XBP1 Promotes Macrophage Survival and Autophagy by Interacting with Beclin-1. Biochem. Biophys. Res. Commun. 463 (4), 518-523. doi:10.1016/j.bbrc.2015.05.061

Tseng, B., P., Green, K., N., Chan, J., L., Blurton-Jones, M., and LaFerla, F., M. (2008). Abeta Inhibits the Proteasome and Enhances Amyloid and Tau Accumulation. Neurobiol. Aging 29 (11), 1607-1618. doi:10.1016/ j.neurobiolaging.2007.04.014

Ugun-Klusek, A., Tatham, M. H., Elkharaz, J., Constantin-Teodosiu, D., Lawler, K., et al. (2017). Continued 26S Proteasome Dysfunction in Mouse Brain Cortical Neurons Impairs Autophagy and the Keap1-Nrf2 Oxidative Defence Pathway. Cel Death Dis. 8 (1), e2531. doi:10.1038/cddis.2016.443

Ulrich, F., U., Bracher, A., and Hayer-Hartl, M. (2011). Molecular Chaperones in Protein Folding and Proteostasis. Nature 475 (7356), 324-332. doi:10.1038/ nature10317

Vallabhapurapu, S., and Karin, M. (2009). Regulation and Function of NF-kappaB Transcription Factors in the Immune System. Annu. Rev. Immunol. 27, 693-733. doi:10.1146/annurev.immunol.021908.132641

Vaughan, D., W., and Peters, A. (1974). Neuroglial Cells in the Cerebral Cortex of Rats from Young Adulthood to Old Age: an Electron Microscope Study. J. Neurocytol. 3 (4), 405-429. doi:10.1007/BF01098730

Vogiatzi, T., Xilouri, M., Vekrellis, K., and Stefanis, L. (2008). Wild Type Alpha-Synuclein Is Degraded by Chaperone-Mediated Autophagy and Macroautophagy in Neuronal Cells. J. Biol. Chem. 283 (35), 23542-23556. doi:10.1074/jbc.M801992200

Wagner, L., K., Gilling, K., E., Schormann, E., Kloetzel, P., M., Heppner, F., L., Krüger, E., et al. (2017). Immunoproteasome Deficiency Alters Microglial Cytokine Response and Improves Cognitive Deficits in Alzheimer's Disease-like APPPS1 Mice. Acta Neuropathol. Commun. 5 (1), 52. doi:10.1186/s40478-017-0453-5

Walter, P., and Ron, D. (2011). The Unfolded Protein Response: from Stress Pathway to Homeostatic Regulation. Science 334 (6059), 1081-1086. doi:10.1126/science.1209038

Wang, X., Chemmama, I. E., Yu, C., Huszagh, A., Xu, Y., et al. (2017). The Proteasome-Interacting Ecm29 Protein Disassembles the 26S Proteasome in Response to Oxidative Stress. J. Biol. Chem. 292 (39), 16310-16320. doi:10.1074/jbc.M117.803619
Wang, X. J., Yu, J., Wong, S., H., Cheng, A., S., Chan, F., K., et al. (2013). A Novel Crosstalk between Two Major Protein Degradation Systems: Regulation of Proteasomal Activity by Autophagy. Autophagy. 9 (10), 1500-1508. doi:10.4161/auto.25573

Wang, X., Yen, J., Kaiser, P., and Huang, L. (2010). Regulation of the $26 \mathrm{~S}$ Proteasome Complex during Oxidative Stress. Sci. Signal. 3 (151), ra88. doi:10.1126/scisignal.2001232

Wei, Y., Liu, M., Li, X., Liu, J., and Li, H. (2018). Origin of the Autophagosome Membrane in Mammals. Biomed. Res. Int. 24, 2018. doi:10.1155/2018/ 1012789

Weibezahn, J., Schlieker, C., Tessarz, P., Mogk, A., and Bukau, B. (2005). Novel Insights into the Mechanism of Chaperone-Assisted Protein Disaggregation. Biol. Chem. 386 (8), 739-744. doi:10.1515/BC.2005.086

Weyh, C., Krüger, K., and Strasser, B. (2020). Physical Activity and Diet Shape the Immune System during Aging. Nutrients. 12 (3), 622. doi:10.3390/nu12030622

Wohlgemuth, S., E., Seo, A., Y., Marzetti, E., Lees, H., A., and Leeuwenburgh, C. (2010). Skeletal Muscle Autophagy and Apoptosis during Aging: Effects of Calorie Restriction and Life-Long Exercise. Exp. Gerontol. 45 (2), 138-148. doi:10.1016/j.exger.2009.11.002

Wolfe, H., Minogue, A. M., Rooney, S., and Lynch, M., A. (2018). Infiltrating Macrophages Contribute to Age-Related Neuroinflammation in C57/BL6 Mice. Mech. Ageing Dev. 173, 84-91. doi:10.1016/j.mad.2018.05.003

Woo, C. W., Kutzler, L., Kimball, S., R., and Tabas, I. (2012). Toll-like Receptor Activation Suppresses ER Stress Factor CHOP and Translation Inhibition through Activation of eIF2B. Nat. Cell Biol. 14 (2), 192-200. doi:10.1038/ ncb2408

Wood, S. H., Craig, T., Li, Y., Merry, B., and de Magalhaes, J. P. (2013). Whole Transcriptome Sequencing of the Aging Rat Brain Reveals Dynamic RNA Changes in the Dark Matter of the Genome. Age (Dordr.). 35, 763-776. doi:10.1007/s11357-012-9410-1

Wu, T., T., Li, W., M., and Yao, Y., M. (2016). Interactions between Autophagy and Inhibitory Cytokines. Int. J. Biol. Sci. 12 (7), 884-897. doi:10.7150/ijbs.15194

Yang, Y., Früh, K., Ahn, K., and Peterson, P., A. (1995). In Vivo assembly of the Proteasomal Complexes, Implications for Antigen Processing. J. Biol. Chem. 270 (46), 27687-27694. doi:10.1074/jbc.270.46.27687

Yu, A., Shibata, Y., Shah, B., Calamini, B., Lo, D. C., and Morimoto, R. I. (2014). Protein Aggregation Can Inhibit Clathrin-Mediated Endocytosis by Chaperone Competition. Proc. Natl. Acad. Sci. U S A. 111 (15), E1481-E1490. doi:10.1073/ pnas.1321811111

Zaiss, D., M., de Graaf, N., and Sijts, A., J. (2008). The Proteasome Immunosubunit Multicatalytic Endopeptidase Complex-like 1 Is a T-Cell-Intrinsic Factor Influencing Homeostatic Expansion. Infect. Immun. 76 (3), 1207-1213. doi:10.1128/IAI.01134-07

Zhang, C., and Cuervo, A., M. (2008). Restoration of Chaperone-Mediated Autophagy in Aging Liver Improves Cellular Maintenance and Hepatic Function. Nat. Med. 14 (9), 959-965. doi:10.1038/nm.1851

Zheng, Q., Su, H., Tian, Z., and Wang, X. (2011). Proteasome Malfunction Activates Macroautophagy in the Heart. Am. J. Cardiovasc. Dis. 1 (3), 214-226.

Zhu, K., Dunner, K., Jr., and McConkey, D., J. (2010). Proteasome Inhibitors Activate Autophagy as a Cytoprotective Response in Human Prostate Cancer Cells. Oncogene. 29, 451-462. doi:10.1038/onc.2009.343

Zmijewski, J., W., Banerjee, S., and Abraham, E. (2009). S-glutathionylation of the Rpn2 Regulatory Subunit Inhibits 26 S Proteasomal Function. J. Biol. Chem. 284 (33), 22213-22221. doi:10.1074/jbc.M109.028902

Conflict of Interest: The author declares that the research was conducted in the absence of any commercial or financial relationships that could be construed as a potential conflict of interest.

Copyright (0 2021 Ruano. This is an open-access article distributed under the terms of the Creative Commons Attribution License (CC BY). The use, distribution or reproduction in other forums is permitted, provided the original author $(s)$ and the copyright owner(s) are credited and that the original publication in this journal is cited, in accordance with accepted academic practice. No use, distribution or reproduction is permitted which does not comply with these terms. 